\title{
NEW INSIGHTS INTO THE SYNERGISTIC EFFECT IN BIMETALLIC-BORON CATALYSTS FOR HYDROGEN GENERATION. THE Co-Ru-B SYSTEM AS A CASE STUDY.
}

\author{
G.M. Arzac, ${ }^{1}$ T.C. Rojas $^{1}$, A. Fernández ${ }^{* 1}$ \\ 1. Instituto de Ciencia de Materiales de Sevilla (ICMS), CSIC-Univ. Sevilla. Américo \\ Vespucio 49. Isla de la Cartuja. Seville. Spain. \\ * Corresponding author.
}

"This paper is dedicated to Prof. Jean Marie Hermann at the occasion of his retirement from his fruitful carrier and strong promotion of international and multicultural exchange of researchers and knowledge" 


\begin{abstract}
Catalysed sodium borohydride hydrolysis is a high-potential method to produce hydrogen for portable applications. Co-B catalysts are the most chosen because they are easily prepared, cheap and efficient. The addition of small amounts of Ru produces a significant enhancement in catalytic activity.

In the present work a series of $\mathrm{Co}-\mathrm{Ru}-\mathrm{B}$ catalysts with variable $\mathrm{Ru}$ content was prepared, isolated and characterized. The comprehension of the synergistic effect was achieved trough the incorporation of the nanostructural dimension to the study of surface and bulk chemical states of the involved atoms along the series. It was found that up to $70 \%$ (of total metal) atomic content of $\mathrm{Ru}$ the catalysts can be considered isostructural to the single Co-B catalyst in the nanoscale. A structural transition occurs in the case of the pure Ru-B material to produce a boron deficient material with higher nanoparticle size. This structural transition together with Co segregation and $\mathrm{Ru}$ dispersion play a key role when explaining a $\left[\mathrm{OH}^{-}\right]$dependant effect.

The inexistence of borate layers in $\mathrm{Ru}$ rich catalysts is suggestive in the research for non deactivating catalysts.
\end{abstract}

\title{
Keywords
}

sodium borohydride hydrolyis , Co-Ru-B catalysts, synergistic effect, nanostructural transition, Ru dispersion.

\section{Introduction}

Catalysed sodium borohydride $\left(\mathrm{NaBH}_{4}, \mathrm{SBH}\right)$ hydrolysis is a promising method to store and supply hydrogen to PEMFCs (Polymer Exchange Membrane Fuel Cells) for portable applications. $\mathrm{H}_{2}$ production occurs according to reaction (1):

$$
\mathrm{NaBH}_{4}+(2+\mathrm{X}) \mathrm{H}_{2} \mathrm{O} \rightarrow 4 \mathrm{H}_{2}+\mathrm{NaBO}_{2} \cdot \mathrm{XH}_{2} \mathrm{O} \quad \text { (1) } \quad \mathrm{X}=2,4
$$

This reaction is being extensively studied and main results and current challenges are summarized in recent review articles [1-2]. The efficiency of hydrogen 
release can be enhanced using appropriate catalysts. Within catalysts, $\mathrm{M}-\mathrm{B}(\mathrm{M}=$ metal $)$ based materials are widely used and can be prepared by chemical reduction of aqueous solutions of metal precursors by SBH. Cobalt is definitely the most selected metal because its efficiency/cost relationship and it has been prepared, characterized and discussed in many works [3-17].

It is well known that the addition of a second metal $\mathrm{M}^{\prime}$ to form an $\mathrm{M}^{-\mathrm{M}^{\prime}-\mathrm{B}}$ material permits to increase significantly the catalytic activity respect to the initial M-B alloy. This enhancement has been proven not only for (1) but also for reactions such us ammonia synthesis, hydrogenation of benzene, $\mathrm{CO}$ and acetonitrile hydrogenation [1822].

Recently, a combinatorial technique was employed to test the catalytic activity of in situ prepared M-Ru-B materials ( $\mathrm{M}=\mathrm{Co}, \mathrm{Ni}, \mathrm{Fe}, \mathrm{Pd}, \mathrm{Ag}, \mathrm{Cu}$ ) for reaction (1) [23]. It was found that the addition of ruthenium (20 mass wt \%) to cobalt produces $250 \%$ enhancement in the activity in comparison to the Co-B mono catalyst. The comprehension of the effect has remained largely descriptive and phenomenological because of the complexity of catalysts composition and microstructure.

In the present work a series of Co-Ru-B catalysts with variable $\mathrm{Ru}$ content was prepared and characterized. The synergistic effect is explained by the incorporation of surface characterization as well as chemical and structural description in the nanoscale at the same extent it was done before for a single Co-B catalyst [24]. The comprehension of the effect was interpreted according to the chemical composition and nanostructural evolution along the Co-Ru-B catalysts series which was investigated through: TEM/EELS (Transmission Electron Microscopy /Electron Energy Loss Spectroscopy, TEM/SAED (Selected Area Electron Diffraction), SEM/EDX (Scanning Electron Microscopy/ Energy Dispersive X-Ray Emission) and XPS (X-Ray Photoelectron Spectroscopy) analysis.

\section{Experimental}

\subsection{Catalysts Preparation}

Catalysts were prepared using a modification of the technique employed before [24]. A discussion about the relationship between preparation, handling, storage conditions and final product is found in references therein. 
Ultrafine Co-Ru-B powder catalysts were prepared by chemical reduction of an aqueous solution of $\mathrm{CoCl}_{2} 6 \mathrm{H}_{2} \mathrm{O}$ and $\mathrm{RuCl}_{3} 3 \mathrm{H}_{2} \mathrm{O}$ with variable $\mathrm{x}_{\mathrm{Ru}}$ (where $\mathrm{x}_{\mathrm{Ru}}$ is considered as $\mathrm{n}_{\text {mol Ru}} /\left(\mathrm{n}_{\mathrm{mol} \mathrm{Ru}}+\mathrm{n}_{\text {mol Co }}\right)$ by aqueous $\mathrm{NaBH}_{4} .15 \mathrm{ml}$ of a $0.424 \mathrm{M}$ total metal solution $(6.37 \mathrm{mmol})$ acidified with $150 \mu \mathrm{l}$ of $\mathrm{HCl}$ (c) was vigorously stirred in a $0^{\circ} \mathrm{C}$ ice bath while $16.4 \mathrm{ml}$ of a $\mathrm{NaBH}_{4} 9$ wt. \% solution (43mmol) was added during 5'. The reaction was left stirring for another $30^{\prime}$ and the solid was filtered and washed thoroughly with water, ethanol and an ethanol/acetone 3:1 mixture. Solvent dry solids are highly pyrophoric especially when $x_{R u} \geq 0.5$. As a passivation procedure, solvent wet solids were dried slowly in air during $24 \mathrm{~h}$ and then were dried in vacuum during $24 \mathrm{hs}$. After this treatment, the products were handled without any particular precautions. Powder catalysts were stored under $\mathrm{N}_{2}$ in a glove box for characterization and in aerobic conditions to assess the stability against oxidation.

Samples are identified by the theoretical Ru content (w) as defined above, by indicating: "X $\mathrm{X}_{\mathrm{Ru}} \mathrm{W}$ sample".

\subsection{Catalytic measurements. Hydrogen Generation (HG) test.}

In a typical experiment, $38 \mathrm{mg}$ of $\mathrm{NaBH}_{4}$ was mixed in a mortar with $3.8 \mathrm{mg}$ of the selected catalyst. The mixture was placed at the bottom of a three necked heart-shaped flask. The flask was immersed in a water bath maintained at $(23 \pm 0.5){ }^{\circ} \mathrm{C}$. The reaction started by injecting $1 \mathrm{ml}$ of a MilliQ ${ }^{\circledR}$ water or $4.5 \mathrm{wt} \% \mathrm{NaOH}$ solution The flask was connected to a $100 \mathrm{ml}$ gas burette and the amount of hydrogen evolved was measured by reading the displacement of a piston (gas-tight by a mercury o-ring) as a function of time. No stirring was used for the experiments, except for the stirring effect of the evolved hydrogen. The HGR (Hydrogen Generation Rate, $\mathrm{ml} \cdot \mathrm{min}^{-1}$ ) was obtained from the slope of the plot of the volume of hydrogen evolved vs. time in linear regime. $\mathrm{HGR}_{\text {cat }}$ was obtained dividing HGR by mass of catalyst employed. Experiments were done by duplicate, and showed to be reproducible.

\subsection{Catalysts characterization}

$\mathrm{X}$-ray diffraction measurements were performed using $\mathrm{Cu} \mathrm{K} \alpha$ radiation in a Siemens D5000 diffractometer in a Bragg-Brentano configuration in the $2 \theta$ angle range of 40-80 degrees. 
XPS spectra were recorded with a Leybold Heraus LH electron spectrometer using Al Ka radiation with $40 \mathrm{eV}$ pass energy at normal emission take off angle. Calibration of $\mathrm{Ru}$ containing samples is a difficult task because of the superposition of $\mathrm{C}(1 \mathrm{~s})$ and $\mathrm{Ru}$ (3d) signals. In case of Co-Ru containing samples, the position of the $2 p_{3 / 2}$ peak of the oxidized cobalt, at $781.2 \mathrm{eV}$ was used as an internal reference for calibration. In the case of $\mathrm{x}_{\mathrm{Ru}}=1$ sample, the absence of $\mathrm{BO}_{2}{ }^{-}$species permitted to assign the $\mathrm{O}$ (1s) singlet to $\mathrm{Ru}-\mathrm{O}$ species, and was taken as second reference peak at $529.2 \mathrm{eV}$ by comparison to ruthenium oxide commercial samples. Reference samples, $\mathrm{RuO}_{2}$ powder and $\mathrm{Ru}$ foil were calibrated according to literature data [25]. Before measurements, the Ru foil was $\mathrm{Ar}^{+}$treated $\left(10^{-5}\right.$ torr $\mathrm{Ar}, 3.5 \mathrm{kV}$ during $\left.8 \mathrm{~min}\right)$ to eliminate the oxide layer.

BET measurements were carried out with a Micromeritics Tristar II equipment. For microscopy studies, the powder samples were impregnated on a copper grid coated with a holey -carbon film. The studies have been performed using two microscopes: A Philips CM 200 with a $2.4 \AA$ resolution equipped with a PEELS spectrometer (GATAN 766-2K) and a high resolution SEM-FEG microscope Hitachi S4800 operating at 5keV where the EDX detector allows the registration of individual elemental mapping.

\section{Results and discussion}

\subsection{Chemical and Nanostructural characterization}

Chemical analyses by plasma ICP (Inductive Coupled Plasma) are shown in table 1. The $\mathrm{S}_{\mathrm{BET}}$ (table 1) indicate that the prepared catalysts are ultrafine powders with similar surface areas for the extreme compositions and variations along the series that show an increase in surface area for samples $\mathrm{x}_{\mathrm{Ru}}=0.5$ and 0.7 .

Powder X-Ray diffraction studies were carried out for the Co-Ru-B series and the results are shown in Fig.1. Up to $\mathrm{x}_{\mathrm{Ru}}=0.13$, powder catalysts are highly amorphous and for higher $\mathrm{Ru}$ content, broad diffraction peaks appear in the expected positions for Co and $\mathrm{Ru}$ metallic phases indicating the growth of very small crystalline domains.

Figure 2 shows SEM images of powder catalysts $\mathrm{x}_{\mathrm{Ru}}=0,0.13,0.7$ and 1 . At this scale, the structure of the series can be considered equal, homogeneous and morphologically described as "cowliflower like". The catalysts appear to be porous and formed by 10-20 $\mathrm{nm}$ spherical particles with a degree of coalescence. SEM-EDX mapping of Ru and Co permits to verify that both metals are homogeneously distributed although the resolution is not enough to give further information in the nano-scale. 
TEM images are shown in figure 3. For $\mathrm{x}_{\mathrm{Ru}}=0,0.13$ and 0.7 samples, the structure can be described as made up by spherical grains of around 20-40 nm diameter size, forming agglomerates with a degree of interconnection. These spherical grains are as well constituted by smaller dark contrast grains embedded in a light contrast matrix. Besides, the whole structure is surrounded by a lighter layer or veil. A difference to previously studied Co-B catalyst [24] is that the external veil looks thinner and in some zones absent when the Ru content increases. Also the size of the small particles inside the big 20-40 nm grains increases with $\mathrm{Ru}$ content.

In case of $\mathrm{x}_{\mathrm{Ru}}=1$ catalyst, the structure is quite different. In this case, the structure is simpler and can be described as composed of small particles, embedded in a low contrast matrix, with neither formation of spherical bigger grains nor existence of any surrounding veil. The small particles with darker contrast are also bigger than in the other samples in agreement with XRD data.

Selected Area Electron Diffraction was recorded for $\mathrm{x}_{\mathrm{Ru}}=$ 0, 0.13, 0.7 and 1 catalysts and results are presented in Fig 3. The broad rings indicate that nanocrystalline phases are present in agreement with XRD data. The patterns show two rings, the first broad ring with $\mathrm{a} \sim 1.9 \AA \mathrm{d}$ spacing and a second ring, with $\mathrm{d}_{\mathrm{hkl}} \sim 1.2 \AA$. Both rings could be assigned to metallic $\mathrm{Co}$ or $\mathrm{Ru}$ phases. No rings characteristic of cobalt borides $(\mathrm{CoB}$, $\mathrm{Co}_{2} \mathrm{~B}$ and $\left.\mathrm{Co}_{3} \mathrm{~B}\right)$, cobalt oxides $\left(\mathrm{CoO}, \mathrm{Co}_{3} \mathrm{O}_{4}\right)$ or ruthenium oxides $\left(\mathrm{RuO}, \mathrm{RuO}_{2}\right)$ are observed. However, these phases could be present in amorphous state.

Surface characterization was performed by XPS measurements on the Co-Ru-B series. Figure 4.a. shows the B 1s level. In a short view, surface boron content decreases with $\mathrm{Ru}$ content. Surface Boron rich catalysts are found for $\mathrm{x}_{\mathrm{Ru}} \leq 0.5$ and surface boron deficient catalysts are found for higher $\mathrm{Ru}$ contents. In the case of $\mathrm{x}_{\mathrm{Ru}}=0$ catalysts, two peaks at $187.4 \pm 0.1 \mathrm{eV}$ and $191.7 \pm 0.1 \mathrm{eV}$ binding energies account for the presence of elemental boron or boron in $\mathrm{Co}_{\mathrm{x}} \mathrm{B}$ and $\mathrm{BO}_{2}{ }^{-}$species respectively [24]. A detailed observation of $\mathrm{O}(1 \mathrm{~s})$ level spectra in figure 4.c. permits to classify the origin of surface oxygen in two groups. Up to $\mathrm{x}_{\mathrm{Ru}}=0.5$ sample, surface oxygen comes from borate species (light contrast veil observed in TEM) while for $\mathrm{x}_{\mathrm{Ru}} \geq 0.7$, oxygen peaks can be attributed to Ru oxide species.

The Co (2p) level spectra are presented in figure 4.d. The $2 p$ doublet at $777.8 \pm 0.1$ and $792.9 \pm 0.1 \mathrm{eV}$ binding energy is assigned to cobalt in metallic $\mathrm{Co}^{0}$ or $\mathrm{Co}_{\mathrm{x}} \mathrm{B}$ and the $2 \mathrm{p}$ doublet at 781.2 \pm 0.1 and 797.1 $\pm 0.1 \mathrm{eV}$ binding energy can be assigned either to cobalt in oxides or $\mathrm{Co}\left(\mathrm{BO}_{2}\right)_{2}$. Up to $\mathrm{x}_{\mathrm{Ru}}=0.5$ samples, the latter assignation seems the most 
realistic by comparison with the $\mathrm{O} 1 \mathrm{~s}$ and $\mathrm{B} 1 \mathrm{~s}$ levels. For $\mathrm{x}_{\mathrm{Ru}}=0.7$ sample, the $2 \mathrm{p}_{1 / 2}$ doublet at 781.2 \pm 0.1 and $797.1 \pm 0.1 \mathrm{eV}$ may be assigned mainly to Co oxides as borate is not visible any more at the surface. The intensity of the $\mathrm{Co}^{0}$ or $\mathrm{Co}_{\mathrm{x}} \mathrm{B}$ signal decreases with $\mathrm{Ru}$ content to disappear completely at $\mathrm{x}_{\mathrm{Ru}}=0.7$ sample.

The study of $\mathrm{Ru}\left(3 \mathrm{~d}\right.$ ) level is possible despite the presence of carbon only if the $\mathrm{d}_{5 / 2}$ peak at $\sim 280 \mathrm{eV}$ is considered (fig 4.b) disregarding the $\mathrm{Ru} 3 \mathrm{~d}_{3 / 2}$ signal overlapping with $\mathrm{C}(1 \mathrm{~s})$. In addition, the $\mathrm{Ru}(3 \mathrm{p})$ doublet was also measured and the result is shown in the supporting information (fig 1). From fig 4.b the position of Ru peaks corresponds to partially reduced $\mathrm{Ru}$ species although it seems that along the Co-Ru series, the position of $\mathrm{Ru}$ signal shifts to lower binding energy. In the case of $\mathrm{Ru}$ rich samples ( $\mathrm{x}_{\mathrm{Ru}}=0.7$ and 1) a high degree of reduction is found as expected from the growth of the metallic crystalline nanodomains .

From all these data, it can be extracted that according to a qualitative description the series can be divided in two groups: those whose surface is dominated by Cobalt/Ruthenium/Boron/Oxygen chemistry for $0 \leq \mathrm{x}_{\mathrm{Ru}} \leq 0.5$ and those whose surface is Ruthenium/Oxygen dominant for $\mathrm{x}_{\mathrm{Ru}} \geq 0.7$. The former group contains mainly metal borides $\mathrm{M}_{\mathrm{x}} \mathrm{B}_{\mathrm{y}}$ or $\mathrm{M}^{0}(\mathrm{M}=\mathrm{Co}, \mathrm{Ru})$ and cobalt borate $\mathrm{Co}\left(\mathrm{BO}_{2}\right)_{2}$ and the latter Ru oxides and $\mathrm{Ru}^{0}$ with a significant contribution of the latter.

Quantitative analysis was made on XPS spectra for the whole series and the results are summarised in Table 2. Surface cobalt content seems to be constant at around $35 \%$ atomic percentage for $\mathrm{x}_{\mathrm{Ru}} \leq 0.7$ while oxygen content seems to be at around $45-55 \%$ atomic percentage for the whole series. However, plasma ICP measurements show that total Co \% content decreases along the series (table 1). Surface boron content decreases and surface ruthenium content increases slowly with $\mathrm{x}_{\mathrm{Ru}}$. Calculation of molar fraction of Ruthenium exposed on surface ( $\mathrm{x}_{\text {Rusurf }}=\mathrm{n}_{\text {Rusurf }} \mathrm{f}\left(\mathrm{n}_{\text {Ru surf }}+\mathrm{n}_{\text {Co surf }}\right)$, (where $\mathrm{n}_{\mathrm{M} \text { surf }}$ represents the atomic percentage of metal "M" that results from XPS quantification), permits to conclude that $\mathrm{x}_{\mathrm{Ru}}$ surface increases very slowly with $\mathrm{Ru}$ content. Clearly, there is a surface segregation of Co for Ru rich samples and will be discussed in section 3.2.2.

Calculation of $\left[\mathrm{B}_{\text {surf }}\right] /\left[\mathrm{M}_{\text {tot surf }}\right]$ (where $\left[\mathrm{B}_{\text {surf }}\right]$ represent the atomic percent of boron and $\left[\mathrm{M}_{\text {totsurf }}\right]$ the total metal atomic percent at surface) and comparison to $[\mathrm{B}]_{\mathrm{ICP}} /\left[\mathrm{M}_{\mathrm{tot}}\right]_{\mathrm{ICP}}$ (table 1) demonstrates that all over the series, there is a surface metal enrichment in respect to boron which indicates a significant degree of dispersion at least up to $\mathrm{x}_{\mathrm{Ru}} 0.5$. 
EELS studies in TEM enable the chemical and electronic investigation of a material. In particular, ELNES (Electron Energy Loss Near Edge Structure) which arises from the energy distribution of the empty electronic states above the Fermi level can provide information on the local coordination. One way to investigate the ELNES features is to record "finger-prints" from the same elemental edge in different compounds and then link the observed features to a specific environment. [26] In this sense the $\mathrm{B}-\mathrm{K}, \mathrm{Ru} \mathrm{M}_{4,5}$ and Co- $\mathrm{L}_{2,3}$ edges have been measured in a conventional TEM, for the series of ultrafine prepared catalysts $\left(\mathrm{x}_{\mathrm{Ru}}=0,0.13,0.7\right.$ and 1$)$, a $\mathrm{Ru}$ foil and a commercial $\mathrm{RuO}_{2}$ sample as references. The area analysed in all measurements is around $50 \mathrm{~nm}^{2}$. It has to be noted that EELS gives information of chemical states of atoms in the whole sample ("bulk measurements") while XPS gives similar information from surface atoms. In this work, both techniques are used, and considered complementary. $\mathrm{B} \mathrm{K}$ edge of prepared catalysts is shown in figure 5.a. For $\mathrm{x}_{\mathrm{Ru}}=0$ sample, the spectrum shows a contribution of B-Co bonds and B-O bonds [24]. For $0.13 \leq \mathrm{x}$ Ru $\leq 0.7$ the $\mathrm{B}-\mathrm{K}$ edge is dominated by the presence of signals coming from B-O bonds, with a smaller contribution of $\mathrm{B}-\mathrm{M}$ bond. For $\mathrm{x}_{\mathrm{Ru}}=1$ sample, the $\mathrm{BK}$ edge shows the presence of $\mathrm{B}$ $\mathrm{Ru}$ and a wide peak attributed to B-O bonds.

The $\mathrm{Ru} \mathrm{M} \mathrm{M}_{4,5}$ edge is found in fig 5.b. By comparison with references, ruthenium seems to be highly reduced all around the series.

Normalised $\mathrm{L}_{2,3}$-Co edges are shown in fig. 5.c. It is well known that the intensities of Co $L_{3}$ and $L_{2}$ edge resonances, or white line ( $2 p \rightarrow 3 d$ transitions), reflect the occurrence of unoccupied states in the $\mathrm{d}$ band. The $\mathrm{L}_{3} / \mathrm{L}_{2}$ area ratio is sensitive to the oxidation state. The higher the $\mathrm{L}_{3} / \mathrm{L}_{2}$ area ratio, the more oxidized. [27-29]. As before we have measured as an approximation, the ratio between the intensity of $\mathrm{L}_{3}$ and $\mathrm{L}_{2}$ white lines in the sample and in reference compounds (a previously prepared $\mathrm{Co}\left(\mathrm{BO}_{2}\right)_{2}$ sample a Co foil and a commercial $\mathrm{Co}_{\mathrm{x}} \mathrm{B}$ sample $\mathrm{x}=2,3$ see ref [24]) and these values can be found in table 3 (average values recorded on at least three representative areas). The $\mathrm{L}_{3} / \mathrm{L}_{2}$ area ratio measured for $\mathrm{x}_{\mathrm{Ru}}=0$ and $\mathrm{x}_{\mathrm{Ru}}=0.7$ samples indicates a high average degree of reduction for cobalt. For $\mathrm{x}_{\mathrm{Ru}}=0.13$ sample, a slight degree of oxidation of cobalt is observed.

EELS bulk analysis has unveiled that $\mathrm{Ru}$ and Co show in average a high degree of metallic character all around the series, despite surface appears oxidized according to XPS. This is expected for the high dispersion of the Co and $\mathrm{Ru}$ phases in these materials. Surface boron deficient samples $\left(x_{R_{u}}=0.7,1\right)$ have a high contribution of $B-M$ 
and B-O signals, which indicates a location of this element in bulk. Borate based species seem to be located on surface when present.

\subsection{Catalytic activity and synergistic effect.}

Hydrogen evolution curves of the Co-Ru-B series in $\mathrm{NaOH} 4.5 \mathrm{wt} \%$ and pure water are found in the supporting information (fig.2) and the most relevant catalytic parameters are summarized in table 4. Curves indicate that reaction is zero order for SBH. Concentration of SBH in tests is $\sim 3.5 \mathrm{wt} \%$, within the reaction- limited kinetic regime $[8]$.

It is known that both Co and $\mathrm{Ru}$ are active catalysts for reaction (1) and independently of the preparation method $\mathrm{Ru}$ is the most active [3]. For the Co-Ru-B alloys it is assumed that both $\mathrm{Co}$ and $\mathrm{Ru}$ atoms are active phases.

It is expected that the addition of $\mathrm{Ru}$ to a Co material leads to an enhancement in catalytic activity. However, synergistic effect is related to the extra catalytic activity of the Co-Ru-B material of a certain $\mathrm{Ru} / \mathrm{Co}$ ( $\mathrm{x}_{\mathrm{Ru}}$ as defined in section 2.1) composition in respect to the sum of two single $\mathrm{Co}-\mathrm{B}$ and $\mathrm{Ru}-\mathrm{B}$ catalysts with the same $\mathrm{Ru} / \mathrm{Co}$ ratio. This sum is represented by the experimental line between $\mathrm{x}_{\mathrm{Ru}} 0$ and 1 . When catalytic activity of the Co- Ru-B catalysts is above this line there is a synergistic effect. On the contrary if catalytic activity falls below this line it is an antagonistic effect. Synergistic effect was also reported for a Co-Fe-B system in which the Fe-B mono catalyst has no activity towards reaction (1) [19].

Figures $7 \mathrm{a}$ and $8 \mathrm{a}$ show HGR values as a function of $\mathrm{x}_{\mathrm{Ru}}$. Figure 7.a. accounts for the presence of a synergistic effect in $\mathrm{NaOH} 4.5 \mathrm{wt} \%$ may be except for the $\mathrm{x}_{\mathrm{Ru}}=0.5$

sample. On the contrary, an apparent antagonistic effect for the Co-Ru catalysts is found in pure water (fig.8.a).

\subsubsection{The role of Nanostructure}

In section 3.1 it was given a detailed structural description through TEM analysis together with a schematic description of the series (fig.6.). To simplify it will be considered that samples up to $\mathrm{x}_{\mathrm{Ru}}=0.7$ are iso-structural in spite of the absence of external veil in the latter sample. The presence of veil can be disregarded considering TEM micrograph (Figure 3) since it is thin and in some zones appears to be absent. 
Under a certain range of thickness the presence of veil does not affect catalytic activity. The $\mathrm{x}_{\mathrm{Ru}}=0$ catalyst prepared in the present work has a thinner veil than the previously reported Co-B (slightly different preparation) and catalytic activity is equal within the experimental error [24]. However it is known that if the veil is thick enough catalysts undergo deactivation [30-31].

Sample $\mathrm{x}_{\mathrm{Ru}}=1$ cannot be considered structurally equal to the rest of the series. In this case nanoparticle size experiments a clear growth that plays a key role in the interpretation of catalytic activity. The low tendency of $\mathrm{Ru}$ to bind $\mathrm{BO}_{2}{ }^{-}$species explain the absence of boron veil when increasing the Ru content and may be an advantage when searching for a non-deactivating catalyst [30-31].

\subsubsection{Surface segregation of Cobalt and Ru high dispersion.}

It is well known that the chemical composition of a surface is usually different from the bulk composition. Segregation of a component is of vital importance in the comprehension of bimetallic alloys. In this case, the system is more complex than a simple Co-Ru binary alloy as is composed of Co-Ru-B-O atoms. Despite this complexity Nørskov’s predictions fit the experimental Co surface enrichment along the series [32]. Nørskov et al calculated the surface segregation energies of transition metal impurities in close packed surface of hosts, and found that for a $\mathrm{Ru}$ host with a Co impurity, the theoretical value is $-0.37 \mathrm{eV}$, which was considered as a "strong segregation" [32]. Also the chemistry of Co and B-O species favours adsorbateinduced segregation effects which are not favoured in the case of $\mathrm{Ru}$.

Along the series surface Co atomic content remains constant while surface $\mathrm{Ru}$ atomic content increases slowly. Ru aggregates at the alloy suface must be smaller and better dispersed that in the case of the single Ru-B. Activity is limited by the increase in particle size and despite the high degree of reduction of $\mathrm{Ru}$.

No direct correlation was found between catalytic activity and surface area measurements. However, the plot of the HGR as a function of $\mathrm{x}_{\text {Rusurf }}$ (fig.7.b) brings to light a $\mathrm{x}_{\text {Rusurf }}$-dependant (or $\mathrm{x}$ Cosurf which is equivalent) activity in $\mathrm{NaOH} 4.5 \mathrm{wt} \%$ which explains why the $\mathrm{x}_{\mathrm{Ru}}=0.5$ sample has the same catalytic activity than the $\mathrm{x}_{\mathrm{Ru}}=$ 0.13 catalyst. Another view of the effect that catalytic activity of Co-B is increased linearly by adding amounts $\mathrm{Ru}$ up to $\mathrm{x}$ Rusurf $=0.2$ sample and then falls from the trend at $\mathrm{x}_{\mathrm{Ru}}=1$ (Fig.7a). 
In Figure 8.b the same plot of HGR vs. $\mathrm{x}_{\text {Rusurf }}$ in pure water does not show the antagonistic effect for the Co-Ru catalysts found in Figure 8a. Here the synergistic effect is negligible.

3.2.3. Synergistic or not. Effect of $\mathrm{NaOH}$ concentration and practical considerations

From the previous sections (3.2.1 and 3.2.2), it was shown that according to previous results a small addition of $\mathrm{Ru}$ to a single $\mathrm{Co}-\mathrm{B}$ catalyst produces a synergistic effect that permits to approach to the catalytic activity of a single noble $\mathrm{Ru}-\mathrm{B}$ material. However it was shown here for the first time that this is a $\left[\mathrm{OH}^{-}\right]$dependent affirmation, since the plot or the HGR as a function of $\mathrm{x}_{\mathrm{Ru} \text { surf }}$ (fig.8.b) in pure water shows a very weak effect. Revankar et al prepared in a previous work single Co-B and Ru-B samples, and made a kinetic comparison between the catalysts in terms of the mechanism proposed by Holbrook and Twist $[8,33]$. For a better comprehension of the role of $\left[\mathrm{OH}^{-}\right]$on synergistic effect, fresh materials were tested under different $\mathrm{NaOH}$ concentration $(0,1$, 2.5, 4.5, 10, 20, $30 \mathrm{wt} \%$ ). Main results are summarized in Fig. 9 and in the supporting information (Figure 2, Figure 3 and table 1).

The study of the effect of $\left[\mathrm{OH}^{-}\right]$on catalytic activity for each catalyst (Fig.9) shows that pure Co-B and Ru-B catalyst have different behaviour. Both Co-B and Ru-B catalysts experiment an increase in catalytic activity from pure water to $1 \mathrm{wt} \% \mathrm{NaOH}$. This increase is abrupt in the case of the Co-B than for slight $\mathrm{Ru}-\mathrm{B}$. Co-B activity is increased with $[\mathrm{NaOH}]$ up to $20 \mathrm{wt} \%$ and then decreases. On the other hand $\mathrm{Ru}-\mathrm{B}$ catalyst begins to decrease at $4.5 \mathrm{wt} \% \mathrm{NaOH}$. The behaviour of the mono catalysts was explained before and is related to the role of $\mathrm{OH}^{-}$in activating the reactivity of $\mathrm{Co}$ and not that of the $\mathrm{Ru}[8]$.

The plot of catalytic activity as a function of $[\mathrm{NaOH}]$ shows that both $\mathrm{x}_{\mathrm{Ru}} 0.13$ and 0.5 materials (Fig.9.a) behave as the single Co-B while the $\mathrm{x}_{\mathrm{Ru}}=0.7$ behaves similar to the pure Ru-B (Fig 9.b).

For practical reasons it is useful to plot for each $\mathrm{NaOH}$ concentration catalytic activity of the series as a function of $\mathrm{x}_{\mathrm{Ru}}$. This information is found in the supporting information ( Fig.3). In the case of pure water, no advantage is found in preparing a Co$\mathrm{Ru}-\mathrm{B}$ material instead of using a mixture of Co-B and Ru-B samples. At $1 \mathrm{wt} \%[\mathrm{NaOH}]$ there is a clear advantage in the case of the $\mathrm{x}_{\mathrm{Ru}}=0.13$ sample, but not for the rest. For increasing $[\mathrm{NaOH}]$ it is clear that the effect is more pronounced. In the extreme $30 \mathrm{wt} \%$ 
$[\mathrm{NaOH}]$ single $\mathrm{Co}-\mathrm{B}$ and $\mathrm{Ru}-\mathrm{B}$ catalyst tend to the same activity, making the use of Co$\mathrm{Ru}-\mathrm{B}$ materials very advantageous at least theoretically. However the use of $30 \mathrm{wt} \%$ $\mathrm{NaOH}$ is not recommended. High viscosity difficults mass transfer to the catalyst surface, reducing the substrate (sodium borohydride) conversion in linear regime. Catalytic activity of the $\mathrm{x}_{\mathrm{Ru}}=0.5$ sample is equal to the $\mathrm{x}_{\mathrm{Ru}}=0.13$ up to $\mathrm{NaOH} 20 \mathrm{wt} \%$ and then tends to be equal to the $\mathrm{x}_{\mathrm{Ru}}=0.7$.

\subsubsection{Stability towards oxidation}

Catalysts stored under aerobic conditions were tested after 11 months. The results are found in table 4 . Up to $\mathrm{x}_{\mathrm{Ru}} \leq 0.7 \mathrm{Co}-\mathrm{Ru}-\mathrm{B}$ catalysts are stable in aerobic conditions (90$98 \%$ of the initial activity retained after 11 months). On the contrary the single Ru-B catalyst has retained only $55 \%$ of the initial activity. This finding supports the protecting role attributed to the amorphous boron containing phases respect to the small metallic cores [24]. The advantage of preparing Co-Ru-B materials is now not only related to the enhancement in catalytic activity but also to stability upon oxidation.

\section{Conclusions}

A series of $\mathrm{Co}-\mathrm{Ru}-\mathrm{B}$ catalysts with variable $\mathrm{Ru}$ content was prepared and characterized in comparison to pure Co-B and Ru-B catalysts to study the synergistic effect. The reaction under investigation was the catalysed sodium borohydride $\left(\mathrm{NaBH}_{4}, \mathrm{SBH}\right)$ hydrolysis as it is a promising method to store and supply hydrogen to PEMFCs for portable applications.

It was found that the degree of the synergistic effect in $\mathrm{Co} / \mathrm{Ru}$ catalysts is $\left[\mathrm{OH}^{-}\right]$ dependent. In particular the study of the reaction in basic medium $(4.5 \mathrm{wt} \% \mathrm{NaOH}$ to $30 \mathrm{wt} \% \mathrm{NaOH}$ ) shows a strong synergistic effect of the catalytic activity when plotted vs. the relative amount of surface $\mathrm{Ru}$ atoms ( $\mathrm{Ru}$ molar fraction in respect to total metal at the surface).

The present paper shows the key role of the nanostructural dimension to understand the synergistic effect. For Ru contents up to 0.7 the microstructure maintains a high degree of dispersion of the active metals. The observed segregation of Co seems to be associated to the conservation of the chemistry and microstructure previously observed in a pure Co-B material. This microstructure is formed by small metal nanoparticles 
embedded in amorphous $\mathrm{Co}-\mathrm{Ru}-\mathrm{B}(\mathrm{O})$ phases. These protected metallic cores, are also the constituents of 20-40nm grains that are covered by an amorphous veil/layer constituted mainly by borates. This layer is responsible of the stability of catalysts stored in aerobic conditions. The layer tends to disappear when the Ru content increases.

For the pure Ru-B catalyst the boron content is strongly reduced with a change in the microstructure, the 20-40 nm grains are not any more distinguishable and the new bigger structures are formed by bigger $\mathrm{Ru}$ particle embedded in a $\mathrm{Ru}-\mathrm{B}(\mathrm{O})$ phase. No borate was found in this case, and this suggests that the Ru-B catalyst could be less sensitive to deactivation but also less stable upon oxidation. The decrease of the amount of boron containing phases on surface explains both effects.

Cobalt-Boron based bimetallic alloys have shown here to be a good choice to replace pure Ru-B because of activity and stability. At present their major drawback is the deactivation processes based in the adsorption of $\mathrm{B}-\mathrm{O}$ species to the $\mathrm{Co}$ rich surface. Nanostructural insights, as well as the study of phase's distribution have been the main contributions of this paper to understand the catalytic properties of the Co-Ru-B system. A $\left[\mathrm{OH}^{-}\right]$dependence of the synergistic effect was shown experimentally in this paper also in agreement with previous mechanistic studies.

The exact crystallite size and the study of the formation of $\mathrm{Co} / \mathrm{Ru}$ alloy phases were not presented here and will be object of a future study. Investigations on the role of the veil in catalytic activity and stability of Ru-B catalyst against deactivation are in progress. 


\section{Acknowledgements:}

Authors thank the financial support from Spanish Ministry MICINN (CTQ2009-13440), the EC (CT-REGPOT-2011-1-285895, AL-NANOFUNC), the CSIC (201060I041, 200460E643) and Junta de Andalucía (TEP217). 


\section{References}

[1] B.H. Liu, Z.P. Li, J. Power Sources, 187, (2009)527-534.

[2] U.B Demirci, O.Akdim, J. Andrieux, J. Hannauer, R. Chamoun, P.Miele, Fuel Cells 3 (2010) 335-350.

[3] H.I. Schlesinger, H.C. Brown, A.E. Finholt, J.R. Gilbreath, H.R. Hoekstra, E.K. Hyde, J. Am. Chem. Soc, 75 (1953) 215-219.

[4] C. Wu, F.Wu, Y. Bai, B. Yi, H. Zhang, Mater. Lett., 59 (2005)1748-1751.

[5]S.U. Jeong, E.A. Cho, S.W. Nam, I.H. Oh, U.H. Jung, S.H. Kim, Int. J. Hydrogen Energy, 32 (2007) 1749-1754.

[6]J. Zhao, H. M, J. Chen, Int. J. Hydrogen Energy, 32 (2007)4711-4716.

[7] J. Lee, K.Y. Kong, C. R. Jung, E. Cho, S.P Yoon, J.Han, T.G Lee, S.W. Nam, Catal. Today, 120, (2007) 305-310.

[8] J.C Walter, A. Zurawski, D. Montgomery, M. Thornburg, S. Revankar, J. Power Sources, 179 (2008)335-339.

[9] H. B. Dai, Y. Liang, P. Wang, H.M. Cheng, J. Power Sources, 177, (2008)17-23.

[11]B.H.Liu, Q.Li, Int J Hydrogen Energy, 33 (2008) 7385-7391.

[12] N. Patel, R. Fernandes, G. Guella, A. Kale, A. Miotello, B. Patton, C. Zanchetta. J Phys Chem C, 112 (2008) 6968-6976.

[13]P. Krishan, S. G. Advani, A.K. Prasad, Int J Hydrogen Energy ,33 (2008) 70957102.

[14] J. Liang, Y. Li, Y. Huang, J. Yang, H. Tang, Z. Wei, Int J Hydrogen Energy, 32 (2008) 4048-4054.

[15] P. Krishnan, S.G. Advani, A.K. Prasad, Appl. Cat. B Envrion, 86 (2009) 137-144

[16] H. Tian, Q. guo, D. Xu, J Power Sources, 195 (2010) 2136-2142.

[17]U.B. Demirci, P.Miele, Phys. Chem. Chem Phys, 12 (2010) 14665-14651.

[18] R. Fernandes, N.Patel, A. Miotello, M. Filippi, J. Mol. Catal. A. 298, (2009)1-6. [19]Y.P. Wang, Y.J. Wang, Q. L. Ren, L. Li, L.F Jiao, D.W. Song, G.Liu, Y. Han, HT. Yuan, Fuel Cells, 10 (2010) 132-138.

[19]A. Armigliato, S. Bigi, P. Moggi, S. Papadopulos, G. Predieri, G. Salviati, E. Sappa, Materials Chemistry and Physics 29, (1991) 251-260. 
[20]H. Wang, Z. Yu, H. Chen, J. Yang, J. Deng, Appl. Cat. A: General, 129, (1995) L143-L149.

[21] A. Kogelbauer, J. Goodwin Jr, R. Oukaci, Journal of Catalysis, 160 (1996)125133.

[22]H.Li, Y. Wu, J. Zhang, W. Dai, M.Qiao, Appl. Cat. A: General, 275 (2004) 199206.

[23] J.H. Park, P. Shakkthivel, H.J. Kim, M.K. Han, J.H. Jang, Y.R. Kim, H.S. Kim, Y.G Shul, Int J. Hydrogen Energy, 33 (2008)1845-1852.

[24]G.M. Arzac, T.C. Rojas, A.Fernández, Chem. Cat Chem, 3 (2011) 1305-1313.

[25]D.Briggs,M.P. Seah, Practical Surface Analysis, Second Edition . John Wiley and Sons. 1990

[26]R.F. Egerton, Electron Energy Loss Spectroscopy in Electron Microscopy, Second ed. Plenunm, New York, 1996.

[27]R.D. Leapman, L.A. Grunes, P.L. Fejes, Phys. Rev. B, 26 (1982) 614.

[28]J.A. Horsley, J. Chem. Phys, 76 (1982)1451.

[29]P.B.Oliate, T.C. Rojas, A. Fernández, A. Gedanken, Y. Koltypin, F. Palacio, Acta Materialia, 52 (2004) 2167-2171.

[30] J.H. Kim, K.T. Kim, Y.M. Kang, H.S. Kim, M.S. Song, Y.J.Lee, P.S.Lee, J.Y. Lee, J.Alloys and Compds, 379, 2004, 222-227.

[31] O.Akdim, U.B. Demirci, P. Miele, Int. J. Hydrogen Energy, 36, 2011, 1366913675.

[32] A.V. Ruban, H.L. Shriver, J.K. Noørskov, Phys. Rev. B, 59 (1999) 15990-16000.

[33]K.A. Holbrook, P.J. Twist, J. Chem. Soc. A, (1971) 890-894. 


\section{Table Legends}

Table 1. Catalysts Characteristics

Table 2. Quantitative results of XPS measurements on the series expressed in atomic percentage

Table 3. EELS parameters at the $\mathrm{Co}_{2,3}$ edge of catalysts and reference samples.

Table 4. Kinetic parameters of prepared samples. 


\section{Figure captions}

Figure 1. XRD pattern for the Co-Ru-B prepared catalysts.

Figure 2. SEM micrographs together with Co and Ru EDX compositional mappings for the indicated Co-Ru-B catalysts.

Figure 3. TEM/SAED micrographs for the indicated Co-Ru-B catalysts.

Figure 4. XPS spectra for the Co-Ru-B prepared series. (a) B (1s), (b) Ru (3d), (c)O1s and (d) Co 2p.

Figure 5. EELS spectra of prepared Co-Ru-B catalysts in comparison to references (indicated in each case). (a) B K edge (b) $\mathrm{Ru} \mathrm{M}_{4,5}$ edge (c) Co $\mathrm{L}_{2,3}$ edge.

Figure 6. Schematic representation of the nanostructure and composition of the studied materials.

Figure 7. Hydrogen Generation rate for the series in $4.5 \mathrm{wt} \% \mathrm{NaOH}$ as a function of (a) $\mathrm{x}_{\mathrm{Ru}}$ and (b) $\mathrm{x}_{\mathrm{Ru}}$ surface

Figure 8 .Hydrogen Generation rate for the series in deionized water as a function of (a) $\mathrm{x}_{\mathrm{Ru}}$ and (b) $\mathrm{x}_{\mathrm{Ru}}$ surface

Figure 9. Hydrolysis rates normalized to the maximum observed for each material as a function of $\mathrm{NaOH}$ wt $\%$ for the (a) $\mathrm{x}_{\mathrm{Ru}}=0,0.13,0.5$ catalysts and (b) $\mathrm{x}_{\mathrm{Ru}}=0.7$ and 1 catalysts. 



\title{
NEW INSIGHTS INTO THE SYNERGISTIC EFFECT IN BIMETALLIC-BORON CATALYSTS FOR HYDROGEN GENERATION. THE Co-Ru-B SYSTEM AS A CASE STUDY.
}

\author{
G.M. Arzac, ${ }^{1}$ T.C. $\operatorname{Rojas}^{1}$, A. Fernández ${ }^{*} 1$ \\ 1. Instituto de Ciencia de Materiales de Sevilla (ICMS), CSIC-Univ. Sevilla. Américo \\ Vespucio 49. Isla de la Cartuja. Seville. Spain. \\ * Corresponding author.
}

"This paper is dedicated to Prof. Jean Marie Hermann at the occasion of his retirement from his fruitful carrier and strong promotion of international and multicultural exchange of researchers and knowledge" 


\begin{abstract}
Catalysed sodium borohydride hydrolysis is a high-potential method to produce hydrogen for portable applications. Co-B catalysts are the most chosen because they are easily prepared, cheap and efficient. The addition of small amounts of Ru produces a significant enhancement in catalytic activity.

In the present work a series of $\mathrm{Co}-\mathrm{Ru}-\mathrm{B}$ catalysts with variable $\mathrm{Ru}$ content was prepared, isolated and characterized. The comprehension of the synergistic effect was achieved trough the incorporation of the nanostructural dimension to the study of surface and bulk chemical states of the involved atoms along the series. It was found that up to $70 \%$ (of total metal) atomic content of $\mathrm{Ru}$ the catalysts can be considered isostructural to the single Co-B catalyst in the nanoscale. A structural transition occurs in the case of the pure Ru-B material to produce a boron deficient material with higher nanoparticle size. This structural transition together with Co segregation and $\mathrm{Ru}$ dispersion play a key role when explaining a $\left[\mathrm{OH}^{-}\right]$dependant effect.

The inexistence of borate layers in $\mathrm{Ru}$ rich catalysts is suggestive in the research for non deactivating catalysts.
\end{abstract}

\title{
Keywords
}

sodium borohydride hydrolyis , Co-Ru-B catalysts, synergistic effect, nanostructural transition, Ru dispersion.

\section{Introduction}

Catalysed sodium borohydride $\left(\mathrm{NaBH}_{4}, \mathrm{SBH}\right)$ hydrolysis is a promising method to store and supply hydrogen to PEMFCs (Polymer Exchange Membrane Fuel Cells) for portable applications. $\mathrm{H}_{2}$ production occurs according to reaction (1):

$$
\mathrm{NaBH}_{4}+(2+\mathrm{X}) \mathrm{H}_{2} \mathrm{O} \rightarrow 4 \mathrm{H}_{2}+\mathrm{NaBO}_{2} \cdot \mathrm{XH}_{2} \mathrm{O} \quad \text { (1) } \quad \mathrm{X}=2,4
$$

This reaction is being extensively studied and main results and current challenges are summarized in recent review articles [1-2]. The efficiency of hydrogen 
release can be enhanced using appropriate catalysts. Within catalysts, $\mathrm{M}-\mathrm{B}(\mathrm{M}=$ metal $)$ based materials are widely used and can be prepared by chemical reduction of aqueous solutions of metal precursors by SBH. Cobalt is definitely the most selected metal because its efficiency/cost relationship and it has been prepared, characterized and discussed in many works [3-17].

It is well known that the addition of a second metal $\mathrm{M}^{\prime}$ to form an $\mathrm{M}^{-\mathrm{M}^{\prime}-\mathrm{B}}$ material permits to increase significantly the catalytic activity respect to the initial M-B alloy. This enhancement has been proven not only for (1) but also for reactions such us ammonia synthesis, hydrogenation of benzene, $\mathrm{CO}$ and acetonitrile hydrogenation [1822].

Recently, a combinatorial technique was employed to test the catalytic activity of in situ prepared M-Ru-B materials ( $\mathrm{M}=\mathrm{Co}, \mathrm{Ni}, \mathrm{Fe}, \mathrm{Pd}, \mathrm{Ag}, \mathrm{Cu}$ ) for reaction (1) [23]. It was found that the addition of ruthenium (20 mass wt \%) to cobalt produces $250 \%$ enhancement in the activity in comparison to the Co-B mono catalyst. The comprehension of the effect has remained largely descriptive and phenomenological because of the complexity of catalysts composition and microstructure.

In the present work a series of $\mathrm{Co}-\mathrm{Ru}-\mathrm{B}$ catalysts with variable $\mathrm{Ru}$ content was prepared and characterized. The synergistic effect is explained by the incorporation of surface characterization as well as chemical and structural description in the nanoscale at the same extent it was done before for a single Co-B catalyst [24]. The comprehension of the effect was interpreted according to the chemical composition and nanostructural evolution along the Co-Ru-B catalysts series which was investigated through: TEM/EELS (Transmission Electron Microscopy /Electron Energy Loss Spectroscopy, TEM/SAED (Selected Area Electron Diffraction), SEM/EDX (Scanning Electron Microscopy/ Energy Dispersive X-Ray Emission) and XPS (X-Ray Photoelectron Spectroscopy) analysis.

\section{Experimental}

\subsection{Catalysts Preparation}

Catalysts were prepared using a modification of the technique employed before [24]. A discussion about the relationship between preparation, handling, storage conditions and final product is found in references therein. 
Ultrafine Co-Ru-B powder catalysts were prepared by chemical reduction of an aqueous solution of $\mathrm{CoCl}_{2} 6 \mathrm{H}_{2} \mathrm{O}$ and $\mathrm{RuCl}_{3} 3 \mathrm{H}_{2} \mathrm{O}$ with variable $\mathrm{x}_{\mathrm{Ru}}$ (where $\mathrm{x}_{\mathrm{Ru}}$ is considered as $\mathrm{n}_{\text {mol Ru}} /\left(\mathrm{n}_{\mathrm{mol} \mathrm{Ru}}+\mathrm{n}_{\text {mol Co }}\right)$ by aqueous $\mathrm{NaBH}_{4} .15 \mathrm{ml}$ of a $0.424 \mathrm{M}$ total metal solution $(6.37 \mathrm{mmol})$ acidified with $150 \mu \mathrm{l}$ of $\mathrm{HCl}$ (c) was vigorously stirred in a $0^{\circ} \mathrm{C}$ ice bath while $16.4 \mathrm{ml}$ of a $\mathrm{NaBH}_{4} 9$ wt. \% solution (43mmol) was added during 5'. The reaction was left stirring for another $30^{\prime}$ and the solid was filtered and washed thoroughly with water, ethanol and an ethanol/acetone 3:1 mixture. Solvent dry solids are highly pyrophoric especially when $\mathrm{x}_{\mathrm{Ru}} \geq 0.5$. As a passivation procedure, solvent wet solids were dried slowly in air during $24 \mathrm{~h}$ and then were dried in vacuum during $24 \mathrm{hs}$. After this treatment, the products were handled without any particular precautions. Powder catalysts were stored under $\mathrm{N}_{2}$ in a glove box for characterization and in aerobic conditions to assess the stability against oxidation.

Samples are identified by the theoretical Ru content (w) as defined above, by indicating: "X $\mathrm{X}_{\mathrm{Ru}} \mathrm{W}$ sample".

\subsection{Catalytic measurements. Hydrogen Generation (HG) test.}

In a typical experiment, $38 \mathrm{mg}$ of $\mathrm{NaBH}_{4}$ was mixed in a mortar with $3.8 \mathrm{mg}$ of the selected catalyst. The mixture was placed at the bottom of a three necked heart-shaped flask. The flask was immersed in a water bath maintained at $(23 \pm 0.5){ }^{\circ} \mathrm{C}$. The reaction started by injecting $1 \mathrm{ml}$ of a MilliQ® water or $4.5 \mathrm{wt} \% \mathrm{NaOH}$ solution The flask was connected to a $100 \mathrm{ml}$ gas burette and the amount of hydrogen evolved was measured by reading the displacement of a piston (gas-tight by a mercury o-ring) as a function of time. No stirring was used for the experiments, except for the stirring effect of the evolved hydrogen. The HGR (Hydrogen Generation Rate, $\mathrm{ml} \cdot \mathrm{min}^{-1}$ ) was obtained from the slope of the plot of the volume of hydrogen evolved vs. time in linear regime. $\mathrm{HGR}_{\text {cat }}$ was obtained dividing HGR by mass of catalyst employed. Experiments were done by duplicate, and showed to be reproducible.

\subsection{Catalysts characterization}

$\mathrm{X}$-ray diffraction measurements were performed using $\mathrm{Cu} \mathrm{K} \alpha$ radiation in a Siemens D5000 diffractometer in a Bragg-Brentano configuration in the $2 \theta$ angle range of 40-80 degrees. 
XPS spectra were recorded with a Leybold Heraus LH electron spectrometer using Al Ka radiation with $40 \mathrm{eV}$ pass energy at normal emission take off angle. Calibration of $\mathrm{Ru}$ containing samples is a difficult task because of the superposition of $\mathrm{C}(1 \mathrm{~s})$ and $\mathrm{Ru}$ (3d) signals. In case of Co-Ru containing samples, the position of the $2 p_{3 / 2}$ peak of the oxidized cobalt, at $781.2 \mathrm{eV}$ was used as an internal reference for calibration. In the case of $\mathrm{x}_{\mathrm{Ru}}=1$ sample, the absence of $\mathrm{BO}_{2}{ }^{-}$species permitted to assign the $\mathrm{O}$ (1s) singlet to $\mathrm{Ru}-\mathrm{O}$ species, and was taken as second reference peak at $529.2 \mathrm{eV}$ by comparison to ruthenium oxide commercial samples. Reference samples, $\mathrm{RuO}_{2}$ powder and $\mathrm{Ru}$ foil were calibrated according to literature data [25]. Before measurements, the Ru foil was $\mathrm{Ar}^{+}$treated $\left(10^{-5}\right.$ torr $\mathrm{Ar}, 3.5 \mathrm{kV}$ during $\left.8 \mathrm{~min}\right)$ to eliminate the oxide layer.

BET measurements were carried out with a Micromeritics Tristar II equipment. For microscopy studies, the powder samples were impregnated on a copper grid coated with a holey -carbon film. The studies have been performed using two microscopes: A Philips CM 200 with a $2.4 \AA$ resolution equipped with a PEELS spectrometer (GATAN 766-2K) and a high resolution SEM-FEG microscope Hitachi S4800 operating at 5keV where the EDX detector allows the registration of individual elemental mapping.

\section{Results and discussion}

\subsection{Chemical and Nanostructural characterization}

Chemical analyses by plasma ICP (Inductive Coupled Plasma) are shown in table 1. The $\mathrm{S}_{\mathrm{BET}}$ (table 1) indicate that the prepared catalysts are ultrafine powders with similar surface areas for the extreme compositions and variations along the series that show an increase in surface area for samples $\mathrm{x}_{\mathrm{Ru}}=0.5$ and 0.7 .

Powder X-Ray diffraction studies were carried out for the Co-Ru-B series and the results are shown in Fig.1. Up to $\mathrm{x}_{\mathrm{Ru}}=0.13$, powder catalysts are highly amorphous and for higher $\mathrm{Ru}$ content, broad diffraction peaks appear in the expected positions for Co and $\mathrm{Ru}$ metallic phases indicating the growth of very small crystalline domains.

Figure 2 shows SEM images of powder catalysts $\mathrm{x}_{\mathrm{Ru}}=0,0.13,0.7$ and 1 . At this scale, the structure of the series can be considered equal, homogeneous and morphologically described as "cowliflower like". The catalysts appear to be porous and formed by 10-20 $\mathrm{nm}$ spherical particles with a degree of coalescence. SEM-EDX mapping of Ru and Co permits to verify that both metals are homogeneously distributed although the resolution is not enough to give further information in the nano-scale. 
TEM images are shown in figure 3. For $\mathrm{x}_{\mathrm{Ru}}=0,0.13$ and 0.7 samples, the structure can be described as made up by spherical grains of around 20-40 nm diameter size, forming agglomerates with a degree of interconnection. These spherical grains are as well constituted by smaller dark contrast grains embedded in a light contrast matrix. Besides, the whole structure is surrounded by a lighter layer or veil. A difference to previously studied Co-B catalyst [24] is that the external veil looks thinner and in some zones absent when the Ru content increases. Also the size of the small particles inside the big 20-40 nm grains increases with Ru content.

In case of $\mathrm{x}_{\mathrm{Ru}}=1$ catalyst, the structure is quite different. In this case, the structure is simpler and can be described as composed of small particles, embedded in a low contrast matrix, with neither formation of spherical bigger grains nor existence of any surrounding veil. The small particles with darker contrast are also bigger than in the other samples in agreement with XRD data.

Selected Area Electron Diffraction was recorded for $\mathrm{x}_{\mathrm{Ru}}=$ 0, 0.13, 0.7 and 1 catalysts and results are presented in Fig 3. The broad rings indicate that nanocrystalline phases are present in agreement with XRD data. The patterns show two rings, the first broad ring with $\mathrm{a} \sim 1.9 \AA \mathrm{d}$ spacing and a second ring, with $\mathrm{d}_{\mathrm{hkl}} \sim 1.2 \AA$. Both rings could be assigned to metallic $\mathrm{Co}$ or Ru phases. No rings characteristic of cobalt borides $(\mathrm{CoB}$, $\mathrm{Co}_{2} \mathrm{~B}$ and $\left.\mathrm{Co}_{3} \mathrm{~B}\right)$, cobalt oxides $\left(\mathrm{CoO}, \mathrm{Co}_{3} \mathrm{O}_{4}\right)$ or ruthenium oxides $\left(\mathrm{RuO}, \mathrm{RuO}_{2}\right)$ are observed. However, these phases could be present in amorphous state.

Surface characterization was performed by XPS measurements on the Co-Ru-B series. Figure 4.a. shows the B 1s level. In a short view, surface boron content decreases with $\mathrm{Ru}$ content. Surface Boron rich catalysts are found for $\mathrm{x}_{\mathrm{Ru}} \leq 0.5$ and surface boron deficient catalysts are found for higher $\mathrm{Ru}$ contents. In the case of $\mathrm{x}_{\mathrm{Ru}}=0$ catalysts, two peaks at $187.4 \pm 0.1 \mathrm{eV}$ and $191.7 \pm 0.1 \mathrm{eV}$ binding energies account for the presence of elemental boron or boron in $\mathrm{Co}_{\mathrm{x}} \mathrm{B}$ and $\mathrm{BO}_{2}{ }^{-}$species respectively [24]. A detailed observation of $\mathrm{O}(1 \mathrm{~s})$ level spectra in figure 4.c. permits to classify the origin of surface oxygen in two groups. Up to $\mathrm{x}_{\mathrm{Ru}}=0.5$ sample, surface oxygen comes from borate species (light contrast veil observed in TEM) while for $\mathrm{x}_{\mathrm{Ru}} \geq 0.7$, oxygen peaks can be attributed to Ru oxide species.

The Co (2p) level spectra are presented in figure 4.d. The $2 p$ doublet at $777.8 \pm 0.1$ and $792.9 \pm 0.1 \mathrm{eV}$ binding energy is assigned to cobalt in metallic $\mathrm{Co}^{0}$ or $\mathrm{Co}_{\mathrm{x}} \mathrm{B}$ and the $2 \mathrm{p}$ doublet at 781.2 \pm 0.1 and 797.1 $\pm 0.1 \mathrm{eV}$ binding energy can be assigned either to cobalt in oxides or $\mathrm{Co}\left(\mathrm{BO}_{2}\right)_{2}$. Up to $\mathrm{x}_{\mathrm{Ru}}=0.5$ samples, the latter assignation seems the most 
realistic by comparison with the $\mathrm{O} 1 \mathrm{~s}$ and $\mathrm{B} 1 \mathrm{~s}$ levels. For $\mathrm{x}_{\mathrm{Ru}}=0.7$ sample, the $2 \mathrm{p}_{1 / 2}$ doublet at 781.2 \pm 0.1 and $797.1 \pm 0.1 \mathrm{eV}$ may be assigned mainly to Co oxides as borate is not visible any more at the surface. The intensity of the $\mathrm{Co}^{0}$ or $\mathrm{Co}_{\mathrm{x}} \mathrm{B}$ signal decreases with $\mathrm{Ru}$ content to disappear completely at $\mathrm{x}_{\mathrm{Ru}}=0.7$ sample.

The study of $\mathrm{Ru}\left(3 \mathrm{~d}\right.$ ) level is possible despite the presence of carbon only if the $\mathrm{d}_{5 / 2}$ peak at $\sim 280 \mathrm{eV}$ is considered (fig 4.b) disregarding the $\mathrm{Ru} 3 \mathrm{~d}_{3 / 2}$ signal overlapping with $\mathrm{C}(1 \mathrm{~s})$. In addition, the $\mathrm{Ru}(3 \mathrm{p})$ doublet was also measured and the result is shown in the supporting information (fig 1). From fig 4.b the position of Ru peaks corresponds to partially reduced $\mathrm{Ru}$ species although it seems that along the Co-Ru series, the position of $\mathrm{Ru}$ signal shifts to lower binding energy. In the case of $\mathrm{Ru}$ rich samples ( $\mathrm{x}_{\mathrm{Ru}}=0.7$ and 1) a high degree of reduction is found as expected from the growth of the metallic crystalline nanodomains .

From all these data, it can be extracted that according to a qualitative description the series can be divided in two groups: those whose surface is dominated by Cobalt/Ruthenium/Boron/Oxygen chemistry for $0 \leq \mathrm{x}_{\mathrm{Ru}} \leq 0.5$ and those whose surface is Ruthenium/Oxygen dominant for $\mathrm{x}_{\mathrm{Ru}} \geq 0.7$. The former group contains mainly metal borides $\mathrm{M}_{\mathrm{x}} \mathrm{B}_{\mathrm{y}}$ or $\mathrm{M}^{0}(\mathrm{M}=\mathrm{Co}, \mathrm{Ru})$ and cobalt borate $\mathrm{Co}\left(\mathrm{BO}_{2}\right)_{2}$ and the latter Ru oxides and $\mathrm{Ru}^{0}$ with a significant contribution of the latter.

Quantitative analysis was made on XPS spectra for the whole series and the results are summarised in Table 2. Surface cobalt content seems to be constant at around 35\% atomic percentage for $\mathrm{x}_{\mathrm{Ru}} \leq 0.7$ while oxygen content seems to be at around $45-55 \%$ atomic percentage for the whole series. However, plasma ICP measurements show that total Co \% content decreases along the series (table 1). Surface boron content decreases and surface ruthenium content increases slowly with $\mathrm{x}_{\mathrm{Ru}}$. Calculation of molar fraction of Ruthenium exposed on surface ( $x_{\text {Rusurf }}=n_{\text {Rusurf }} /\left(n_{\text {Ru surf }}+n_{\text {Co surf }}\right)$, (where $n_{M \text { surf }}$ represents the atomic percentage of metal "M" that results from XPS quantification), permits to conclude that $\mathrm{x}_{\mathrm{Ru}}$ surface increases very slowly with Ru content. Clearly, there is a surface segregation of Co for Ru rich samples and will be discussed in section 3.2.2.

Calculation of $\left[\mathrm{B}_{\text {surf }}\right] /\left[\mathrm{M}_{\text {tot surf }}\right]$ (where $\left[\mathrm{B}_{\text {surf }}\right]$ represent the atomic percent of boron and $\left[\mathrm{M}_{\mathrm{totsurf}}\right]$ the total metal atomic percent at surface) and comparison to $[\mathrm{B}]_{\mathrm{ICP}} /\left[\mathrm{M}_{\mathrm{tot}}\right]_{\mathrm{ICP}}$ (table 1) demonstrates that all over the series, there is a surface metal enrichment in respect to boron which indicates a significant degree of dispersion at least up to $\mathrm{x}_{\mathrm{Ru}} 0.5$. 
EELS studies in TEM enable the chemical and electronic investigation of a material. In particular, ELNES (Electron Energy Loss Near Edge Structure) which arises from the energy distribution of the empty electronic states above the Fermi level can provide information on the local coordination. One way to investigate the ELNES features is to record "finger-prints" from the same elemental edge in different compounds and then link the observed features to a specific environment. [26] In this sense the $\mathrm{B}-\mathrm{K}, \mathrm{Ru} \mathrm{M}_{4,5}$ and Co- $\mathrm{L}_{2,3}$ edges have been measured in a conventional TEM, for the series of ultrafine prepared catalysts $\left(\mathrm{x}_{\mathrm{Ru}}=0,0.13,0.7\right.$ and 1$)$, a $\mathrm{Ru}$ foil and a commercial $\mathrm{RuO}_{2}$ sample as references. The area analysed in all measurements is around $50 \mathrm{~nm}^{2}$. It has to be noted that EELS gives information of chemical states of atoms in the whole sample ("bulk measurements") while XPS gives similar information from surface atoms. In this work, both techniques are used, and considered complementary. $\mathrm{B} \mathrm{K}$ edge of prepared catalysts is shown in figure 5.a. For $\mathrm{x}_{\mathrm{Ru}}=0$ sample, the spectrum shows a contribution of B-Co bonds and B-O bonds [24]. For $0.13 \leq \mathrm{x}$ Ru $\leq 0.7$ the $\mathrm{B}-\mathrm{K}$ edge is dominated by the presence of signals coming from B-O bonds, with a smaller contribution of $\mathrm{B}-\mathrm{M}$ bond. For $\mathrm{x}_{\mathrm{Ru}}=1$ sample, the $\mathrm{BK}$ edge shows the presence of $\mathrm{B}$ $\mathrm{Ru}$ and a wide peak attributed to B-O bonds.

The $\mathrm{Ru} \mathrm{M} \mathrm{M}_{4,5}$ edge is found in fig 5.b. By comparison with references, ruthenium seems to be highly reduced all around the series.

Normalised $\mathrm{L}_{2,3}$-Co edges are shown in fig. 5.c. It is well known that the intensities of Co $L_{3}$ and $L_{2}$ edge resonances, or white line ( $2 p \rightarrow 3 d$ transitions), reflect the occurrence of unoccupied states in the $d$ band. The $\mathrm{L}_{3} / \mathrm{L}_{2}$ area ratio is sensitive to the oxidation state. The higher the $\mathrm{L}_{3} / \mathrm{L}_{2}$ area ratio, the more oxidized. [27-29]. As before we have measured as an approximation, the ratio between the intensity of $\mathrm{L}_{3}$ and $\mathrm{L}_{2}$ white lines in the sample and in reference compounds (a previously prepared $\mathrm{Co}\left(\mathrm{BO}_{2}\right)_{2}$ sample a Co foil and a commercial $\mathrm{Co}_{\mathrm{x}} \mathrm{B}$ sample $\mathrm{x}=2,3$ see ref [24]) and these values can be found in table 3 (average values recorded on at least three representative areas). The $\mathrm{L}_{3} / \mathrm{L}_{2}$ area ratio measured for $\mathrm{x}_{\mathrm{Ru}}=0$ and $\mathrm{x}_{\mathrm{Ru}}=0.7$ samples indicates a high average degree of reduction for cobalt. For $\mathrm{x}_{\mathrm{Ru}}=0.13$ sample, a slight degree of oxidation of cobalt is observed.

EELS bulk analysis has unveiled that $\mathrm{Ru}$ and Co show in average a high degree of metallic character all around the series, despite surface appears oxidized according to XPS. This is expected for the high dispersion of the Co and $\mathrm{Ru}$ phases in these materials. Surface boron deficient samples $\left(x_{R_{u}}=0.7,1\right)$ have a high contribution of $B-M$ 
and B-O signals, which indicates a location of this element in bulk. Borate based species seem to be located on surface when present.

\subsection{Catalytic activity and synergistic effect.}

Hydrogen evolution curves of the Co-Ru-B series in $\mathrm{NaOH} 4.5 \mathrm{wt} \%$ and pure water are found in the supporting information (fig.2) and the most relevant catalytic parameters are summarized in table 4. Curves indicate that reaction is zero order for SBH. Concentration of $\mathrm{SBH}$ in tests is $\sim 3.5 \mathrm{wt} \%$, within the reaction- limited kinetic regime [8].

It is known that both $\mathrm{Co}$ and $\mathrm{Ru}$ are active catalysts for reaction (1) and independently of the preparation method $\mathrm{Ru}$ is the most active [3]. For the Co-Ru-B alloys it is assumed that both $\mathrm{Co}$ and $\mathrm{Ru}$ atoms are active phases.

It is expected that the addition of $\mathrm{Ru}$ to a Co material leads to an enhancement in catalytic activity. However, synergistic effect is related to the extra catalytic activity of the Co-Ru-B material of a certain $\mathrm{Ru} / \mathrm{Co}\left(\mathrm{x}_{\mathrm{Ru}}\right.$ as defined in section 2.1) composition in respect to the sum of two single $\mathrm{Co}-\mathrm{B}$ and $\mathrm{Ru}-\mathrm{B}$ catalysts with the same $\mathrm{Ru} / \mathrm{Co}$ ratio. This sum is represented by the experimental line between $\mathrm{x}_{\mathrm{Ru}} 0$ and 1 . When catalytic activity of the Co-Ru-B catalysts is above this line there is a synergistic effect. On the contrary if catalytic activity falls below this line it is an antagonistic effect. Synergistic effect was also reported for a Co-Fe-B system in which the Fe-B mono catalyst has no activity towards reaction (1) [19].

Figures $7 \mathrm{a}$ and $8 \mathrm{a}$ show HGR values as a function of $\mathrm{x}_{\mathrm{Ru}}$. Figure 7.a. accounts for the presence of a synergistic effect in $\mathrm{NaOH} 4.5 \mathrm{wt} \%$ may be except for the $\mathrm{x}_{\mathrm{Ru}}=0.5$ sample. On the contrary, an apparent antagonistic effect for the Co-Ru catalysts is found in pure water (fig.8.a).

\subsubsection{The role of Nanostructure}

In section 3.1 it was given a detailed structural description through TEM analysis together with a schematic description of the series (fig.6.). To simplify it will be considered that samples up to $\mathrm{x}_{\mathrm{Ru}}=0.7$ are iso-structural in spite of the absence of external veil in the latter sample. The presence of veil can be disregarded considering TEM micrograph (Figure 3) since it is thin and in some zones appears to be absent. 
Under a certain range of thickness the presence of veil does not affect catalytic activity. The $\mathrm{x}_{\mathrm{Ru}}=0$ catalyst prepared in the present work has a thinner veil than the previously reported Co-B (slightly different preparation) and catalytic activity is equal within the experimental error [24]. However it is known that if the veil is thick enough catalysts undergo deactivation [30-31].

Sample $\mathrm{x}_{\mathrm{Ru}}=1$ cannot be considered structurally equal to the rest of the series. In this case nanoparticle size experiments a clear growth that plays a key role in the interpretation of catalytic activity. The low tendency of $\mathrm{Ru}$ to bind $\mathrm{BO}_{2}^{-}$species explain the absence of boron veil when increasing the Ru content and may be an advantage when searching for a non-deactivating catalyst [30-31].

\subsubsection{Surface segregation of Cobalt and Ru high dispersion.}

It is well known that the chemical composition of a surface is usually different from the bulk composition. Segregation of a component is of vital importance in the comprehension of bimetallic alloys. In this case, the system is more complex than a simple Co-Ru binary alloy as is composed of Co-Ru-B-O atoms. Despite this complexity Nørskov’s predictions fit the experimental Co surface enrichment along the series [32]. Nørskov et al calculated the surface segregation energies of transition metal impurities in close packed surface of hosts, and found that for a $\mathrm{Ru}$ host with a Co impurity, the theoretical value is $-0.37 \mathrm{eV}$, which was considered as a "strong segregation" [32]. Also the chemistry of Co and B-O species favours adsorbateinduced segregation effects which are not favoured in the case of $\mathrm{Ru}$.

Along the series surface Co atomic content remains constant while surface $\mathrm{Ru}$ atomic content increases slowly. Ru aggregates at the alloy suface must be smaller and better dispersed that in the case of the single Ru-B. Activity is limited by the increase in particle size and despite the high degree of reduction of $\mathrm{Ru}$.

No direct correlation was found between catalytic activity and surface area measurements. However, the plot of the HGR as a function of $\mathrm{x}_{\text {Rusurf }}$ (fig.7.b) brings to light a $\mathrm{x}_{\text {Rusurf }}$-dependant (or $\mathrm{x}_{\text {Cosurf }}$ which is equivalent) activity in $\mathrm{NaOH} 4.5 \mathrm{wt} \%$ which explains why the $\mathrm{x}_{\mathrm{Ru}}=0.5$ sample has the same catalytic activity than the $\mathrm{x}_{\mathrm{Ru}}=$ 0.13 catalyst. Another view of the effect that catalytic activity of Co-B is increased linearly by adding amounts $\mathrm{Ru}$ up to $\mathrm{x}_{\text {Rusurf }}=0.2$ sample and then falls from the trend at $\mathrm{x}_{\mathrm{Ru}}=1$ (Fig.7a). 
In Figure 8.b the same plot of HGR vs. $\mathrm{x}_{\text {Rusurf }}$ in pure water does not show the antagonistic effect for the Co-Ru catalysts found in Figure 8a. Here the synergistic effect is negligible.

3.2.3. Synergistic or not. Effect of $\mathrm{NaOH}$ concentration and practical considerations

From the previous sections (3.2.1 and 3.2.2), it was shown that according to previous results a small addition of $\mathrm{Ru}$ to a single $\mathrm{Co}-\mathrm{B}$ catalyst produces a synergistic effect that permits to approach to the catalytic activity of a single noble $\mathrm{Ru}-\mathrm{B}$ material. However it was shown here for the first time that this is a $\left[\mathrm{OH}^{-}\right]$dependent affirmation, since the plot or the HGR as a function of $\mathrm{x}_{\mathrm{Ru} \text { surf }}$ (fig.8.b) in pure water shows a very weak effect. Revankar et al prepared in a previous work single Co-B and Ru-B samples, and made a kinetic comparison between the catalysts in terms of the mechanism proposed by Holbrook and Twist $[8,33]$. For a better comprehension of the role of $\left[\mathrm{OH}^{-}\right]$on synergistic effect, fresh materials were tested under different $\mathrm{NaOH}$ concentration $(0,1$, 2.5, 4.5, 10, 20, $30 \mathrm{wt} \%$ ). Main results are summarized in Fig. 9 and in the supporting information (Figure 2, Figure 3 and table 1).

The study of the effect of $\left[\mathrm{OH}^{-}\right]$on catalytic activity for each catalyst (Fig.9) shows that pure Co-B and Ru-B catalyst have different behaviour. Both Co-B and Ru-B catalysts experiment an increase in catalytic activity from pure water to $1 \mathrm{wt} \% \mathrm{NaOH}$. This increase is abrupt in the case of the Co-B than for slight $\mathrm{Ru}-\mathrm{B}$. Co-B activity is increased with $[\mathrm{NaOH}]$ up to $20 \mathrm{wt} \%$ and then decreases. On the other hand $\mathrm{Ru}-\mathrm{B}$ catalyst begins to decrease at $4.5 \mathrm{wt} \% \mathrm{NaOH}$. The behaviour of the mono catalysts was explained before and is related to the role of $\mathrm{OH}^{-}$in activating the reactivity of $\mathrm{Co}$ and not that of the $\mathrm{Ru}[8]$.

The plot of catalytic activity as a function of $[\mathrm{NaOH}]$ shows that both $\mathrm{x}_{\mathrm{Ru}} 0.13$ and 0.5 materials (Fig.9.a) behave as the single Co-B while the $\mathrm{x}_{\mathrm{Ru}}=0.7$ behaves similar to the pure Ru-B (Fig 9.b).

For practical reasons it is useful to plot for each $\mathrm{NaOH}$ concentration catalytic activity of the series as a function of $\mathrm{x}_{\mathrm{Ru}}$. This information is found in the supporting information ( Fig.3). In the case of pure water, no advantage is found in preparing a Co$\mathrm{Ru}-\mathrm{B}$ material instead of using a mixture of $\mathrm{Co}-\mathrm{B}$ and $\mathrm{Ru}-\mathrm{B}$ samples. At $1 \mathrm{wt} \%[\mathrm{NaOH}]$ there is a clear advantage in the case of the $\mathrm{x}_{\mathrm{Ru}}=0.13$ sample, but not for the rest. For increasing $[\mathrm{NaOH}]$ it is clear that the effect is more pronounced. In the extreme $30 \mathrm{wt} \%$ 
$[\mathrm{NaOH}]$ single $\mathrm{Co}-\mathrm{B}$ and $\mathrm{Ru}-\mathrm{B}$ catalyst tend to the same activity, making the use of Co$\mathrm{Ru}-\mathrm{B}$ materials very advantageous at least theoretically. However the use of 30wt $\%$ $\mathrm{NaOH}$ is not recommended. High viscosity difficults mass transfer to the catalyst surface, reducing the substrate (sodium borohydride) conversion in linear regime. Catalytic activity of the $\mathrm{x}_{\mathrm{Ru}}=0.5$ sample is equal to the $\mathrm{x}_{\mathrm{Ru}}=0.13$ up to $\mathrm{NaOH} 20 \mathrm{wt} \%$ and then tends to be equal to the $\mathrm{x}_{\mathrm{Ru}}=0.7$.

\subsubsection{Stability towards oxidation}

Catalysts stored under aerobic conditions were tested after 11 months. The results are found in table 4 . Up to $\mathrm{x}_{\mathrm{Ru}} \leq 0.7 \mathrm{Co}-\mathrm{Ru}-\mathrm{B}$ catalysts are stable in aerobic conditions (90$98 \%$ of the initial activity retained after 11 months). On the contrary the single Ru-B catalyst has retained only $55 \%$ of the initial activity. This finding supports the protecting role attributed to the amorphous boron containing phases respect to the small metallic cores [24]. The advantage of preparing Co-Ru-B materials is now not only related to the enhancement in catalytic activity but also to stability upon oxidation.

\section{Conclusions}

A series of $\mathrm{Co}-\mathrm{Ru}-\mathrm{B}$ catalysts with variable $\mathrm{Ru}$ content was prepared and characterized in comparison to pure $\mathrm{Co}-\mathrm{B}$ and $\mathrm{Ru}-\mathrm{B}$ catalysts to study the synergistic effect. The reaction under investigation was the catalysed sodium borohydride $\left(\mathrm{NaBH}_{4}, \mathrm{SBH}\right)$ hydrolysis as it is a promising method to store and supply hydrogen to PEMFCs for portable applications.

It was found that the degree of the synergistic effect in $\mathrm{Co} / \mathrm{Ru}$ catalysts is $\left[\mathrm{OH}^{-}\right]$ dependent. In particular the study of the reaction in basic medium $(4.5 \mathrm{wt} \% \mathrm{NaOH}$ to $30 \mathrm{wt} \% \mathrm{NaOH}$ ) shows a strong synergistic effect of the catalytic activity when plotted vs. the relative amount of surface $\mathrm{Ru}$ atoms ( $\mathrm{Ru}$ molar fraction in respect to total metal at the surface).

The present paper shows the key role of the nanostructural dimension to understand the synergistic effect. For Ru contents up to 0.7 the microstructure maintains a high degree of dispersion of the active metals. The observed segregation of Co seems to be associated to the conservation of the chemistry and microstructure previously observed in a pure Co-B material. This microstructure is formed by small metal nanoparticles 
embedded in amorphous $\mathrm{Co}-\mathrm{Ru}-\mathrm{B}(\mathrm{O})$ phases. These protected metallic cores, are also the constituents of 20-40nm grains that are covered by an amorphous veil/layer constituted mainly by borates. This layer is responsible of the stability of catalysts stored in aerobic conditions. The layer tends to disappear when the Ru content increases.

For the pure Ru-B catalyst the boron content is strongly reduced with a change in the microstructure, the 20-40 nm grains are not any more distinguishable and the new bigger structures are formed by bigger $\mathrm{Ru}$ particle embedded in a $\mathrm{Ru}-\mathrm{B}(\mathrm{O})$ phase. No borate was found in this case, and this suggests that the Ru-B catalyst could be less sensitive to deactivation but also less stable upon oxidation. The decrease of the amount of boron containing phases on surface explains both effects.

Cobalt-Boron based bimetallic alloys have shown here to be a good choice to replace pure $\mathrm{Ru}-\mathrm{B}$ because of activity and stability. At present their major drawback is the deactivation processes based in the adsorption of $\mathrm{B}-\mathrm{O}$ species to the $\mathrm{Co}$ rich surface. Nanostructural insights, as well as the study of phase's distribution have been the main contributions of this paper to understand the catalytic properties of the Co-Ru-B system. A $\left[\mathrm{OH}^{-}\right]$dependence of the synergistic effect was shown experimentally in this paper also in agreement with previous mechanistic studies.

The exact crystallite size and the study of the formation of $\mathrm{Co} / \mathrm{Ru}$ alloy phases were not presented here and will be object of a future study. Investigations on the role of the veil in catalytic activity and stability of Ru-B catalyst against deactivation are in progress. 


\section{Acknowledgements:}

Authors thank the financial support from Spanish Ministry MICINN (CTQ2009-13440), the EC (CT-REGPOT-2011-1-285895, AL-NANOFUNC), the CSIC (201060I041, 200460E643) and Junta de Andalucía (TEP217). 


\section{References}

[1] B.H. Liu, Z.P. Li, J. Power Sources, 187, (2009)527-534.

[2] U.B Demirci, O.Akdim, J. Andrieux, J. Hannauer, R. Chamoun, P.Miele, Fuel Cells 3 (2010) 335-350.

[3] H.I. Schlesinger, H.C. Brown, A.E. Finholt, J.R. Gilbreath, H.R. Hoekstra, E.K. Hyde, J. Am. Chem. Soc, 75 (1953) 215-219.

[4] C. Wu, F.Wu, Y. Bai, B. Yi, H. Zhang, Mater. Lett., 59 (2005)1748-1751.

[5]S.U. Jeong, E.A. Cho, S.W. Nam, I.H. Oh, U.H. Jung, S.H. Kim, Int. J. Hydrogen Energy, 32 (2007) 1749-1754.

[6]J. Zhao, H. M, J. Chen, Int. J. Hydrogen Energy, 32 (2007)4711-4716.

[7] J. Lee, K.Y. Kong, C. R. Jung, E. Cho, S.P Yoon, J.Han, T.G Lee, S.W. Nam, Catal. Today, 120, (2007) 305-310.

[8] J.C Walter, A. Zurawski, D. Montgomery, M. Thornburg, S. Revankar, J. Power Sources, 179 (2008)335-339.

[9] H. B. Dai, Y. Liang, P. Wang, H.M. Cheng, J. Power Sources, 177, (2008)17-23.

[11]B.H.Liu, Q.Li, Int J Hydrogen Energy, 33 (2008) 7385-7391.

[12] N. Patel, R. Fernandes, G. Guella, A. Kale, A. Miotello, B. Patton, C. Zanchetta. J Phys Chem C, 112 (2008) 6968-6976.

[13]P. Krishan, S. G. Advani, A.K. Prasad, Int J Hydrogen Energy ,33 (2008) 70957102.

[14] J. Liang, Y. Li, Y. Huang, J. Yang, H. Tang, Z. Wei, Int J Hydrogen Energy, 32 (2008) 4048-4054.

[15] P. Krishnan, S.G. Advani, A.K. Prasad, Appl. Cat. B Envrion, 86 (2009) 137-144

[16] H. Tian, Q. guo, D. Xu, J Power Sources, 195 (2010) 2136-2142.

[17]U.B. Demirci, P.Miele, Phys. Chem. Chem Phys, 12 (2010) 14665-14651.

[18] R. Fernandes, N.Patel, A. Miotello, M. Filippi, J. Mol. Catal. A. 298, (2009)1-6. [19]Y.P. Wang, Y.J. Wang, Q. L. Ren, L. Li, L.F Jiao, D.W. Song, G.Liu, Y. Han, HT. Yuan, Fuel Cells, 10 (2010) 132-138.

[19]A. Armigliato, S. Bigi, P. Moggi, S. Papadopulos, G. Predieri, G. Salviati, E. Sappa, Materials Chemistry and Physics 29, (1991) 251-260. 
[20]H. Wang, Z. Yu, H. Chen, J. Yang, J. Deng, Appl. Cat. A: General, 129, (1995) L143-L149.

[21] A. Kogelbauer, J. Goodwin Jr, R. Oukaci, Journal of Catalysis, 160 (1996)125133.

[22]H.Li, Y. Wu, J. Zhang, W. Dai, M.Qiao, Appl. Cat. A: General, 275 (2004) 199206.

[23] J.H. Park, P. Shakkthivel, H.J. Kim, M.K. Han, J.H. Jang, Y.R. Kim, H.S. Kim, Y.G Shul, Int J. Hydrogen Energy, 33 (2008)1845-1852.

[24]G.M. Arzac, T.C. Rojas, A.Fernández, Chem. Cat Chem, 3 (2011) 1305-1313.

[25]D.Briggs,M.P. Seah, Practical Surface Analysis, Second Edition . John Wiley and Sons. 1990

[26]R.F. Egerton, Electron Energy Loss Spectroscopy in Electron Microscopy, Second ed. Plenunm, New York, 1996.

[27]R.D. Leapman, L.A. Grunes, P.L. Fejes, Phys. Rev. B, 26 (1982) 614.

[28]J.A. Horsley, J. Chem. Phys, 76 (1982)1451.

[29]P.B.Oliate, T.C. Rojas, A. Fernández, A. Gedanken, Y. Koltypin, F. Palacio, Acta Materialia, 52 (2004) 2167-2171.

[30] J.H. Kim, K.T. Kim, Y.M. Kang, H.S. Kim, M.S. Song, Y.J.Lee, P.S.Lee, J.Y. Lee, J.Alloys and Compds, 379, 2004, 222-227.

[31] O.Akdim, U.B. Demirci, P. Miele, Int. J. Hydrogen Energy, 36, 2011, 1366913675.

[32] A.V. Ruban, H.L. Shriver, J.K. Noørskov, Phys. Rev. B, 59 (1999) 15990-16000.

[33]K.A. Holbrook, P.J. Twist, J. Chem. Soc. A, (1971) 890-894. 


\section{Table Legends}

Table 1. Catalysts Characteristics

Table 2. Quantitative results of XPS measurements on the series expressed in atomic percentage

Table 3. EELS parameters at the $\mathrm{Co}_{2,3}$ edge of catalysts and reference samples.

Table 4. Kinetic parameters of prepared samples. 


\section{Figure captions}

Figure 1. XRD pattern for the Co-Ru-B prepared catalysts.

Figure 2. SEM micrographs together with Co and Ru EDX compositional mappings for the indicated Co-Ru-B catalysts.

Figure 3. TEM/SAED micrographs for the indicated Co-Ru-B catalysts.

Figure 4. XPS spectra for the Co-Ru-B prepared series. (a) B (1s), (b) Ru (3d), (c)O1s and (d) Co 2p.

Figure 5. EELS spectra of prepared Co-Ru-B catalysts in comparison to references (indicated in each case). (a) B K edge (b) $\mathrm{Ru} \mathrm{M}_{4,5}$ edge (c) Co $\mathrm{L}_{2,3}$ edge.

Figure 6. Schematic representation of the nanostructure and composition of the studied materials.

Figure 7. Hydrogen Generation rate for the series in $4.5 \mathrm{wt} \% \mathrm{NaOH}$ as a function of (a) $\mathrm{x}_{\mathrm{Ru}}$ and (b) $\mathrm{x}_{\mathrm{Ru}}$ surface

Figure 8 .Hydrogen Generation rate for the series in deionized water as a function of (a) $\mathrm{x}_{\mathrm{Ru}}$ and (b) $\mathrm{x}_{\mathrm{Ru}}$ surface

Figure 9. Hydrolysis rates normalized to the maximum observed for each material as a function of $\mathrm{NaOH} w t \%$ for the (a) $\mathrm{x}_{\mathrm{Ru}}=0,0.13,0.5$ catalysts and (b) $\mathrm{x}_{\mathrm{Ru}}=0.7$ and 1 catalysts. 



\section{TABLE 1}

\begin{tabular}{ccccc}
\hline Catalyst & $\begin{array}{c}{ }^{\mathrm{C}} \text { Experimental } \\
\mathrm{X}_{\mathrm{Ru}}\end{array}$ & $\begin{array}{c}{ }^{2}[\mathrm{~B}] /[\mathrm{M}]_{\text {tot }} \\
\text { ratio }\end{array}$ & $\begin{array}{c}{ }^{3} \% \text { mass } \\
\text { Co }\end{array}$ & $\begin{array}{c}\mathrm{S}_{\mathrm{BET}} \\
\left(\mathrm{m}^{2} \cdot \mathrm{g}^{-1}\right)\end{array}$ \\
\hline $\mathrm{X}_{\mathrm{Ru}}=0$ & 0 & 0.5 & 78.04 & 24 \\
$\mathrm{X}_{\mathrm{Ru}}=0.13$ & 0.12 & 0.43 & 61.62 & 22 \\
$\mathrm{X}_{\mathrm{Ru}}=0.5$ & 0.42 & 0.33 & 32.85 & 29 \\
$\mathrm{X}_{\mathrm{Ru}}=0.7$ & 0.63 & 0.10 & 16.19 & 32 \\
$\mathrm{X}_{\mathrm{Ru}}=1$ & 1 & 0.04 & 0 & 26 \\
\hline
\end{tabular}

1Obtained with experimental measurements of mass percentage of Co and Ru measured by ICP.

$2[\mathrm{~B}] /[\mathrm{M}]_{\text {tot }}$ ratio represents the ratio between Boron atomic percent and total metal $(\mathrm{Ru}+\mathrm{Co})$ atomic percent obtained by ICP 3 Obtained by plasma ICP measurements 
TABLE 2

\begin{tabular}{c|c|c|c|c|c|c} 
Catalyst & $\begin{array}{c}\mathbf{\%} \mathbf{C o} \\
\mathbf{2 p} \\
\mathbf{s u r f}\end{array}$ & $\begin{array}{c}\mathbf{\%} \mathbf{R u} \\
\mathbf{3 p} \\
\mathbf{s u r f}\end{array}$ & $\begin{array}{c}\mathbf{X}_{\mathbf{R u}} \\
\mathbf{S u r f}\end{array}$ & $\mathbf{\% O}$ & $\mathbf{\%} \mathbf{B}$ & {$\left[\mathbf{B}_{\text {surf }}\right] /\left[\mathbf{M}_{\text {tot surf }}\right]$} \\
\hline $\mathbf{x}_{\mathbf{R u}}=\mathbf{0}$ & 39 & - & $\mathbf{0}$ & 44 & $\mathbf{1 0}$ & 0.256 \\
\hline $\mathbf{x}_{\mathbf{R u}}=\mathbf{0 . 1 3}$ & 33 & 3.7 & $\mathbf{0 . 1}$ & 54 & $\mathbf{8 . 5}$ & 0.232 \\
\hline $\mathbf{x}_{\mathbf{R u}}=\mathbf{0 . 5}$ & 39 & 5.3 & $\mathbf{0 . 1 2}$ & 49 & $\mathbf{5 . 7 7}$ & 0.130 \\
\hline $\mathbf{X}_{\mathbf{R u}}=\mathbf{0 . 7}$ & 34.2 & 9.45 & $\mathbf{0 . 2 2}$ & 47 & - & $\sim 0$ \\
\hline $\mathbf{X}_{\mathbf{R u}}=\mathbf{1}$ & - & 44.13 & $\mathbf{1}$ & & & $\sim 0$
\end{tabular}


TABLE 3

\begin{tabular}{cc}
\hline Catalyst & $\mathbf{L}_{\mathbf{3}} / \mathbf{L}_{\mathbf{2}}$ intensities \\
\hline $\mathrm{X}_{\mathrm{Ru}}=0$ & 1.4 \\
$\mathrm{x}_{\mathrm{Ru}}=0.13$ & 1.7 \\
$\mathrm{x}_{\mathrm{Ru}}=0.7$ & 1.3 \\
${ }^{1}$ Prepared Co $\left(\mathrm{BO}_{2}\right)_{2}$ & $2.5-2$ \\
${ }^{1}$ Metallic $\mathrm{Co}$ & 1.40 \\
${ }^{1}$ Commercial $\mathrm{Co}_{\mathrm{x}} \mathrm{B}$ & 1.36 \\
\hline
\end{tabular}

1 Published previously in [24]. 
TABLE 4

\begin{tabular}{|c|c|c|c|c|c|c|}
\hline Catalyst & $\begin{array}{r}\mathbf{X}_{\mathbf{R u}} \\
\text { Surf. }\end{array}$ & $\begin{array}{c}\text { HGR } \\
\left(\mathrm{ml}^{\left.-m_{i n}^{-1}\right)}\right. \\
\mathrm{NaOH}\end{array}$ & $\begin{array}{c}\text { HGRcat } \\
\left(\text { ml.min }^{1} \text { gcat }^{-1}\right) \\
\text { NaOH }\end{array}$ & $\begin{array}{c}\text { HGR } \\
\left(\mathbf{m l}^{-m^{-1}}\right) \\
\text { MilliQ }\end{array}$ & $\begin{array}{c}\text { HGRcat } \\
\left.\text { (ml.min }^{1} \text { gcat }^{-1}\right) \\
\text { MilliQ }\end{array}$ & $\begin{array}{c}1 \% \text { Activity } \\
\text { retained after } 11 \\
\text { months }\end{array}$ \\
\hline $\mathbf{x}_{\mathrm{Ru}}=\mathbf{0}$ & 0 & 4 & 1052 & 1.8 & 474 & $98 \%$ \\
\hline $\mathrm{X}_{\mathrm{Ru}}=\mathbf{0 . 1 3}$ & 0.1 & 12 & 3158 & 4.23 & 1113 & $90 \%$ \\
\hline $\mathrm{x}_{\mathrm{Ru}}=0.5$ & 0.12 & 11 & 2894 & 7.13 & 1876 & $91 \%$ \\
\hline$X_{R u}=0.7$ & 0.22 & 20 & 5263 & 8 & 2105 & $96 \%$ \\
\hline $\mathrm{X}_{\mathrm{Ru}}=1$ & 1 & 18 & 4737 & 20.5 & 5395 & $55 \%$ \\
\hline
\end{tabular}

1 Under aerobic storage. Calculated as

(Activity of fresh catalyst)x100/(activity of the 11 months old catalyst) 


\section{FIGURE 1}

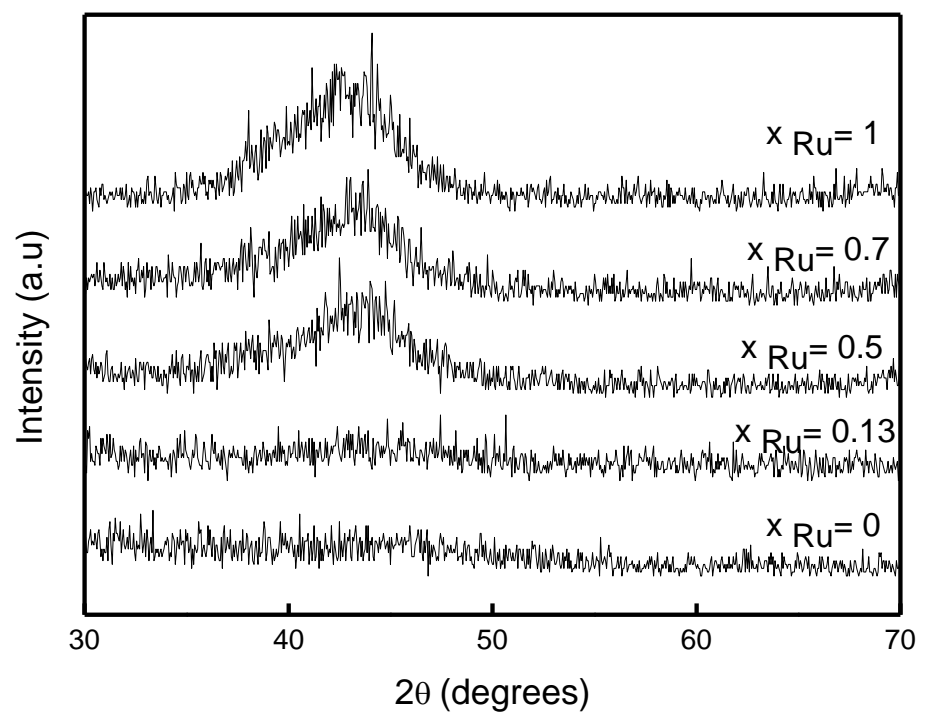




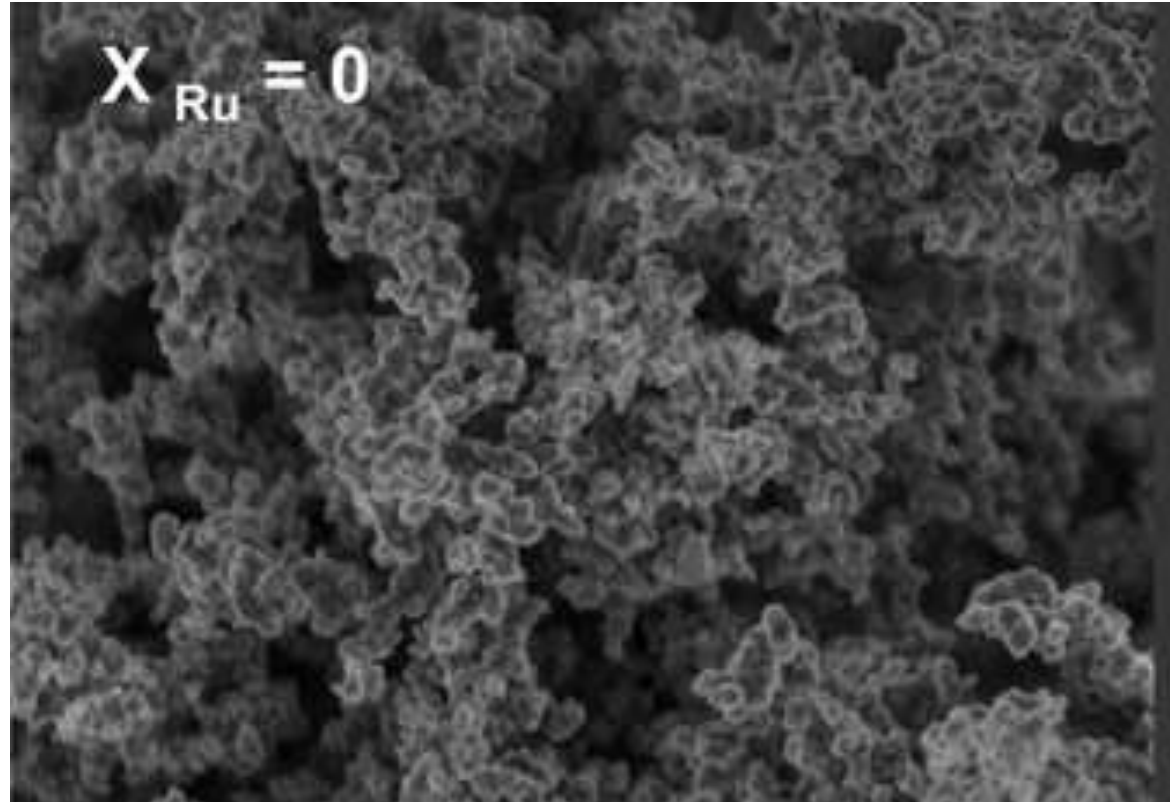

$$
X_{\mathrm{Ru}}=0.13
$$

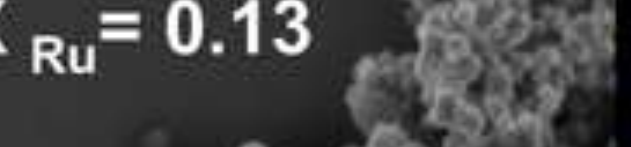

$\times 45.0 \mathrm{k}$, $1.00 \mathrm{ur} \times 45.0 \mathrm{~K}$
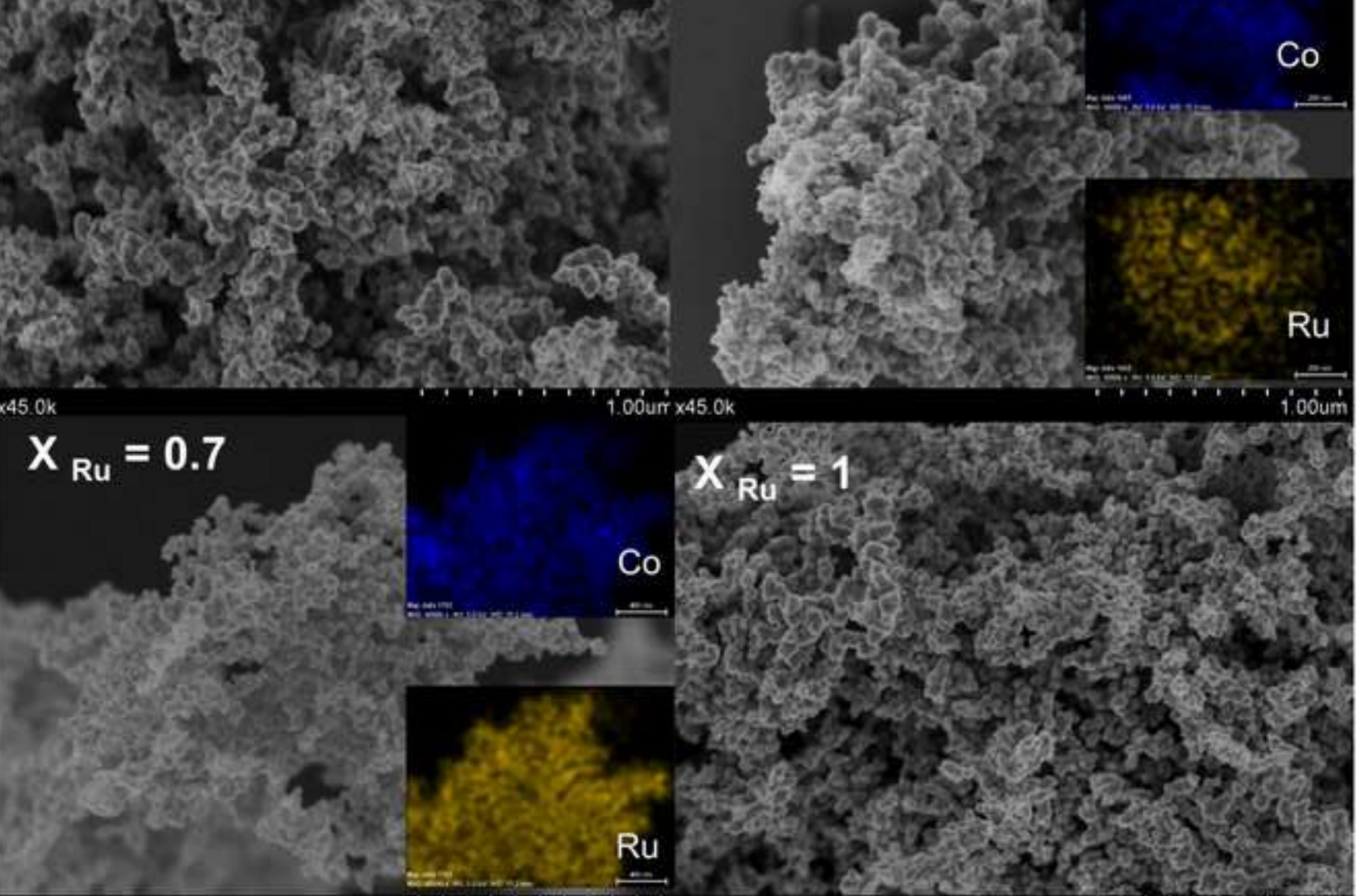


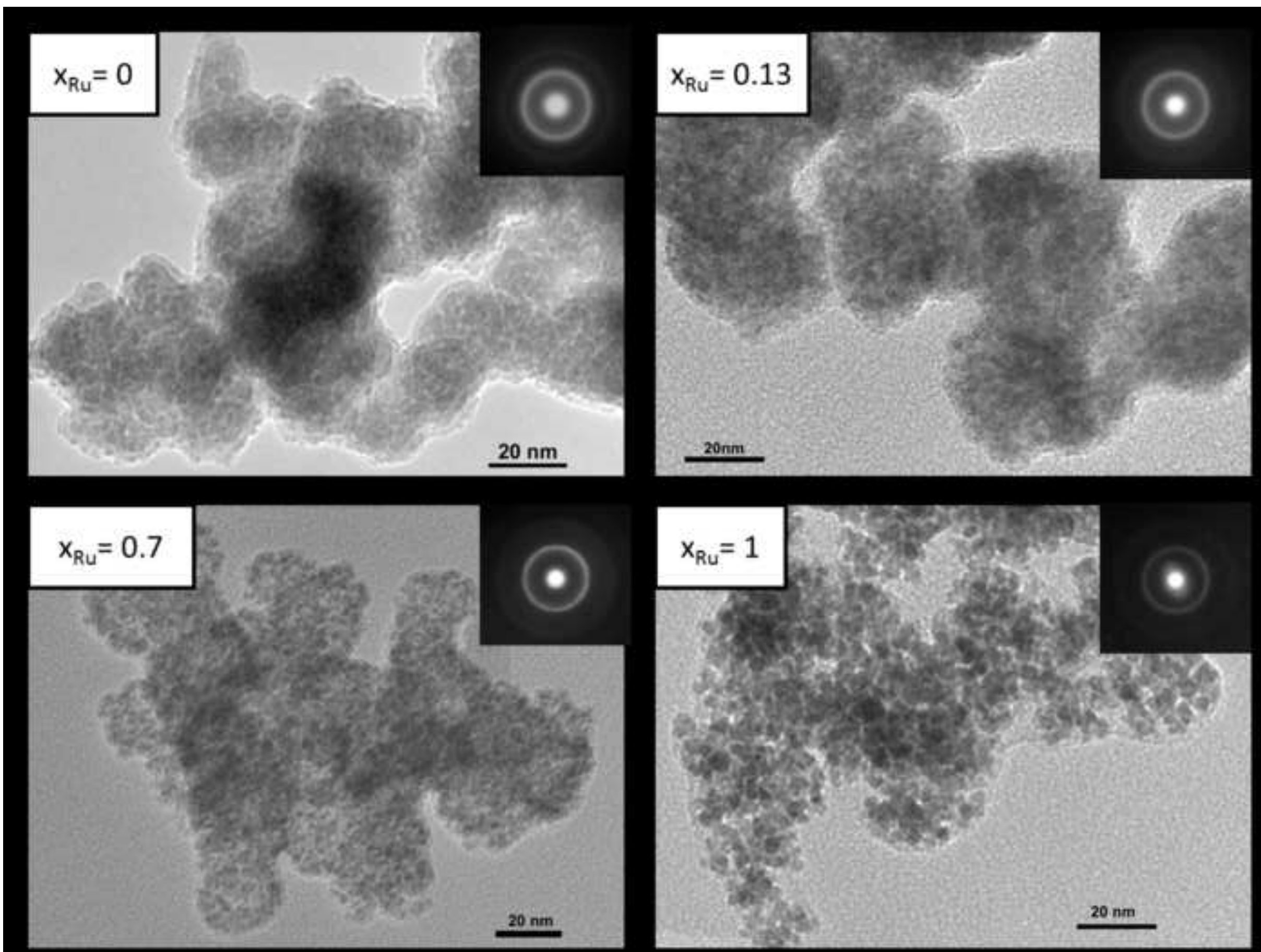


FIGURE 4

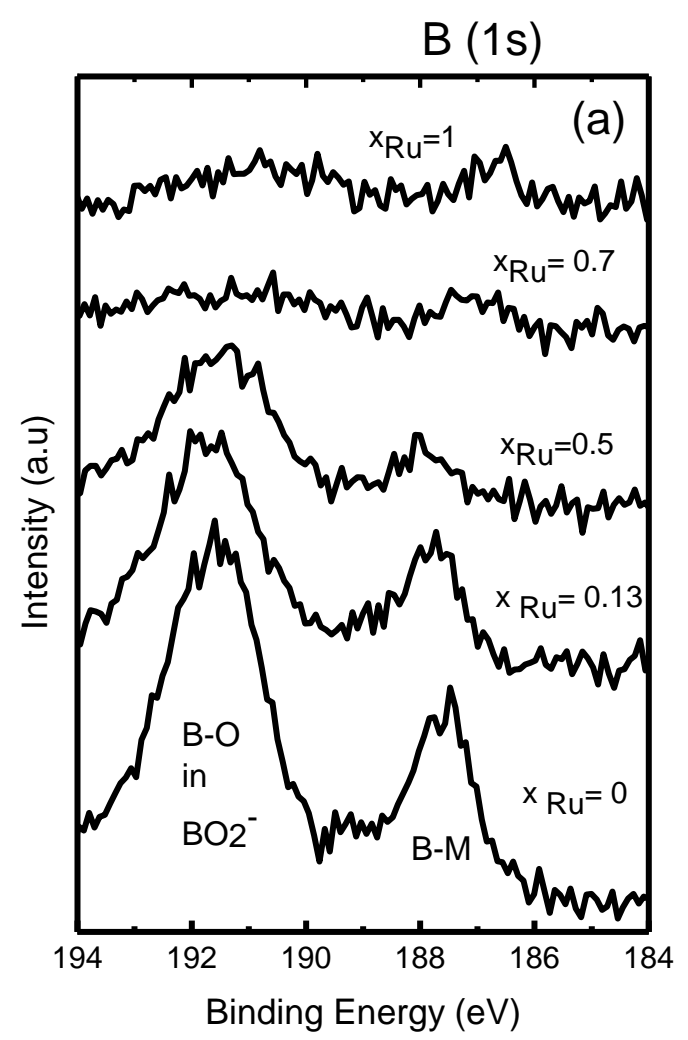

$\mathrm{O}(1 \mathrm{~s})$

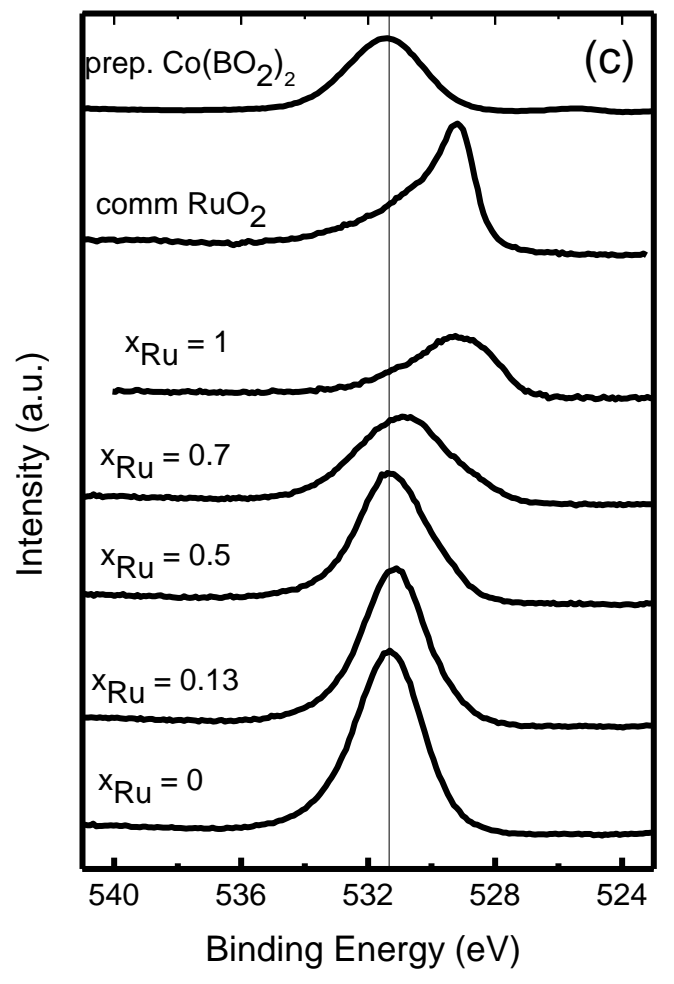

$\mathrm{Ru}$ (3d)

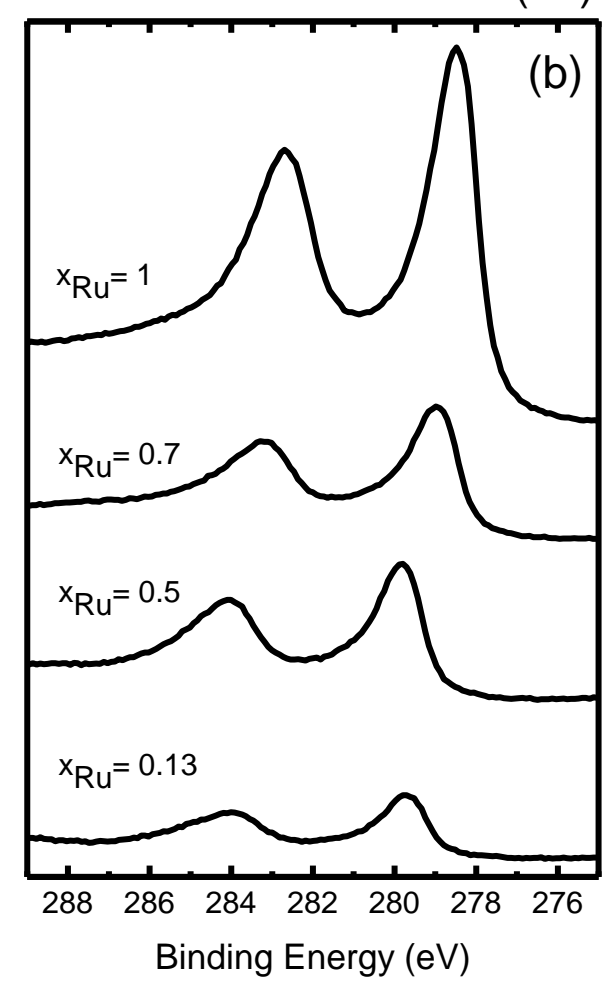

Co (2p)

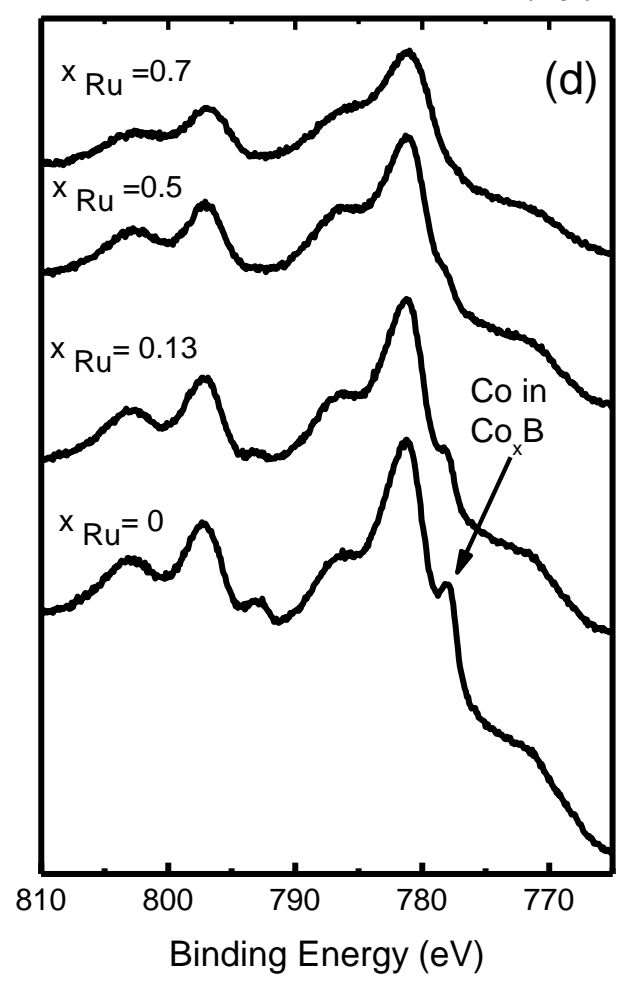


Figure 5
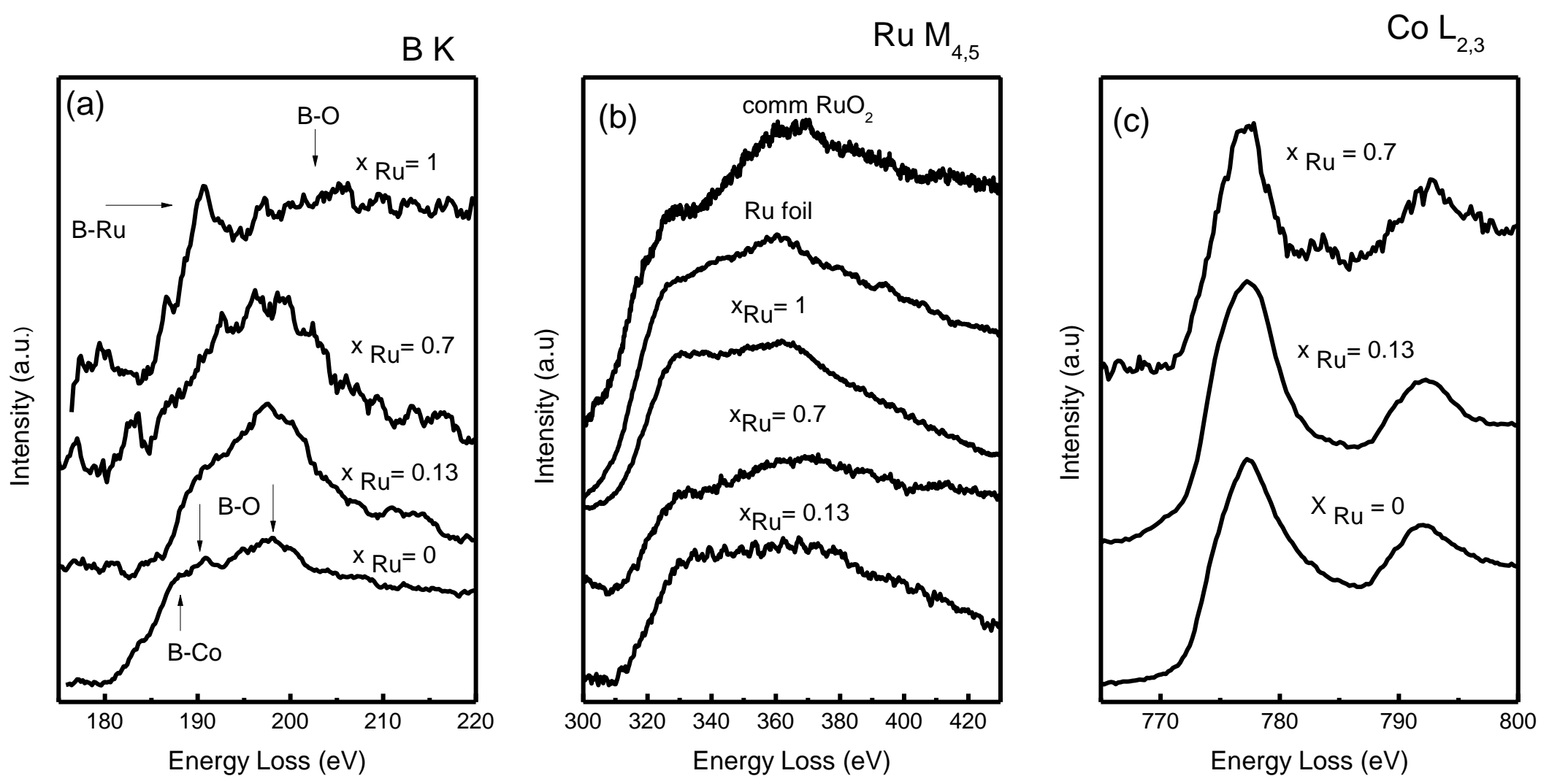


\section{Figure 6}

Co-B

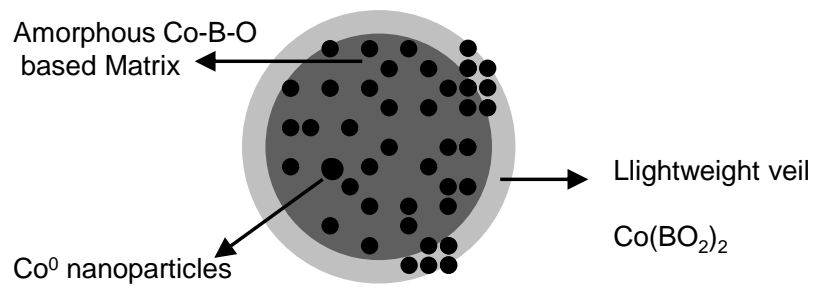

Co-Ru-B $x_{R u}=0.7$

Amorphous Ru-Co-B-O based Matrix

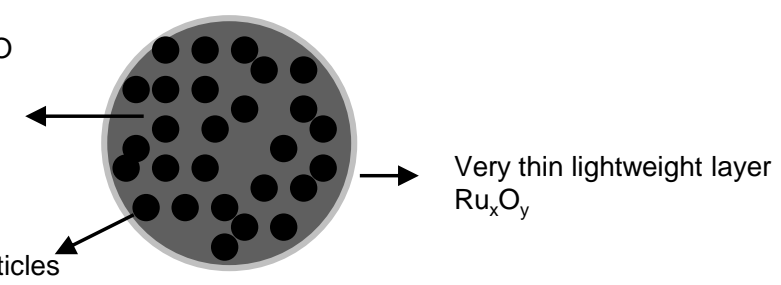

Co-Ru-B $x_{R u}=0.13$

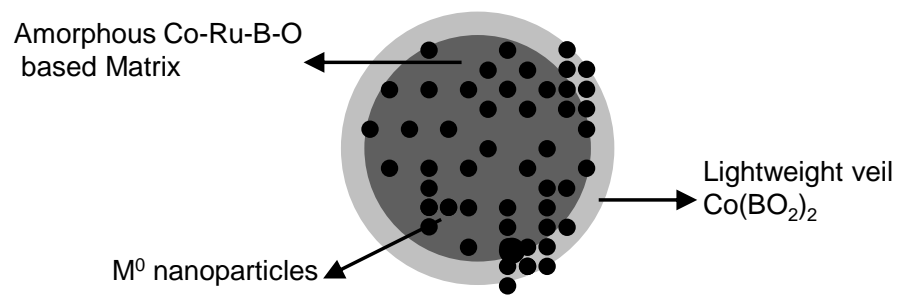

Ru-B

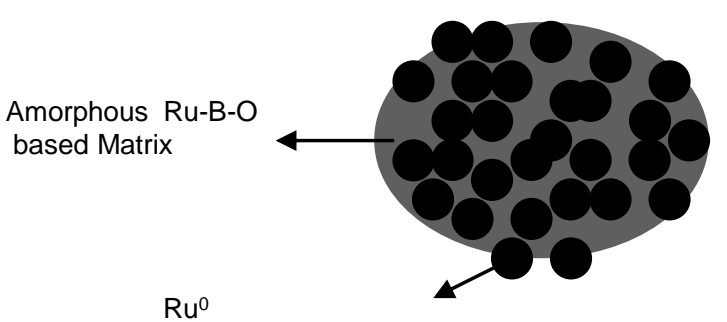

$\mathrm{Ru}^{0}$

nanoparticles 
FIGURE 7
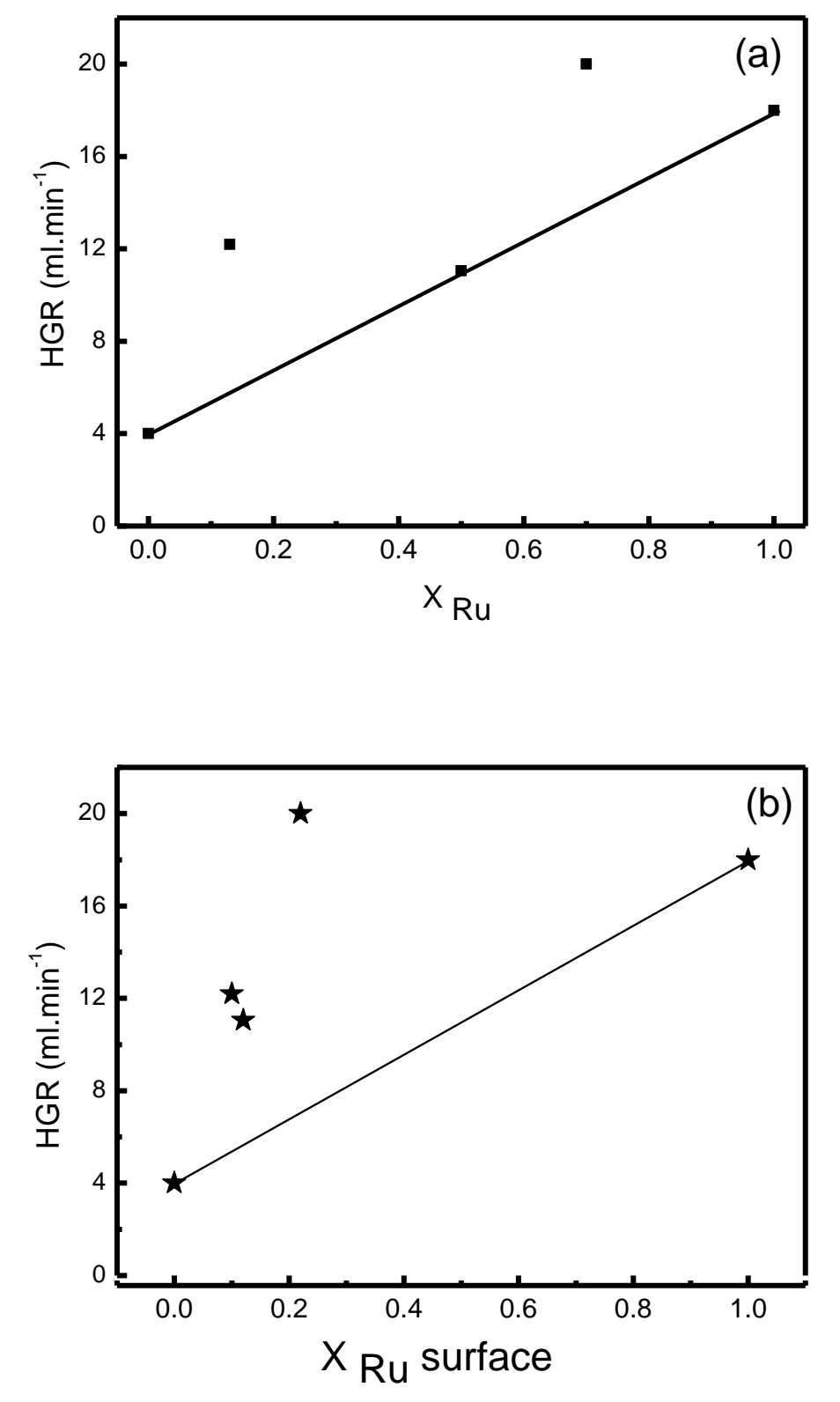

(b) 
FIGURE 8
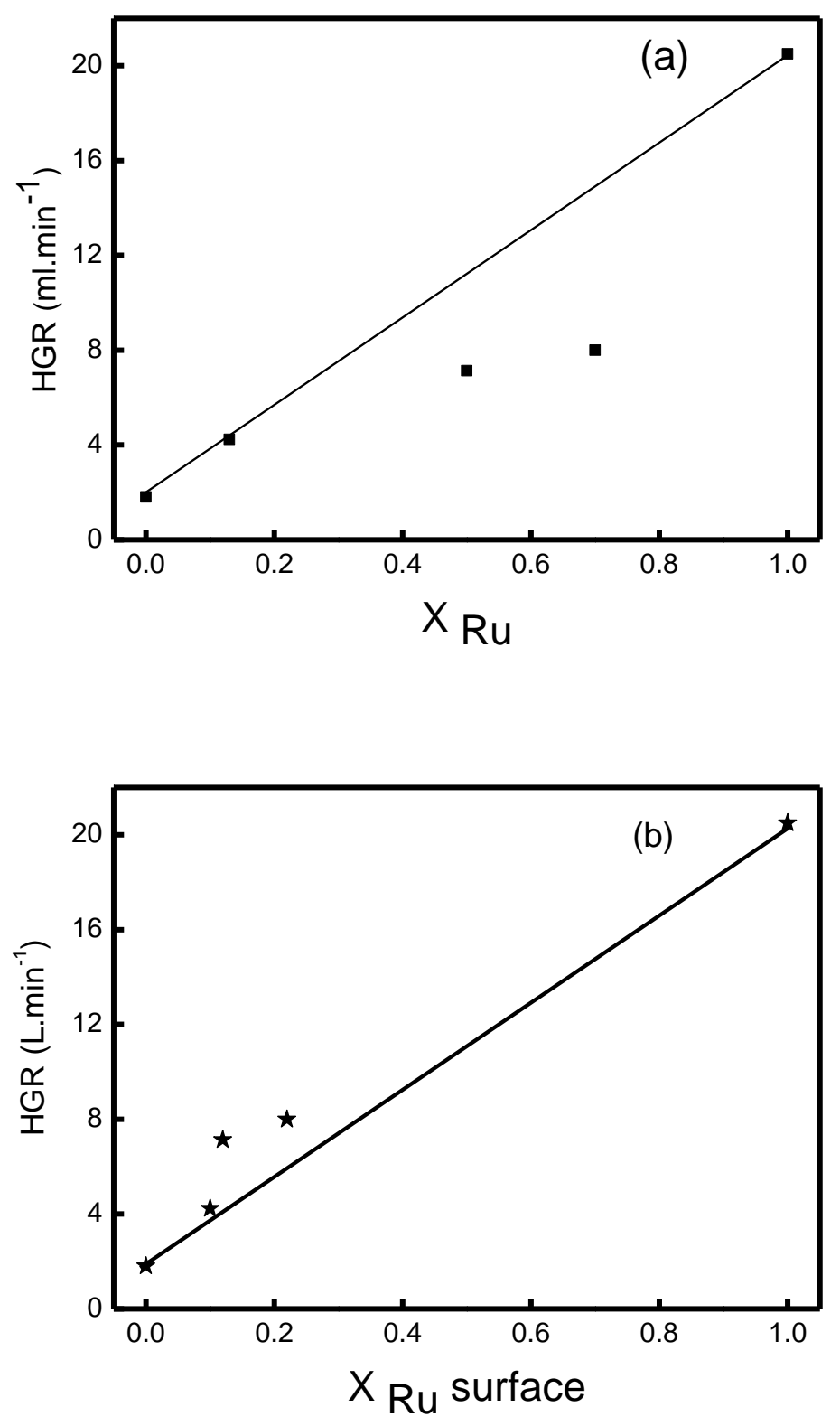
Figure 9
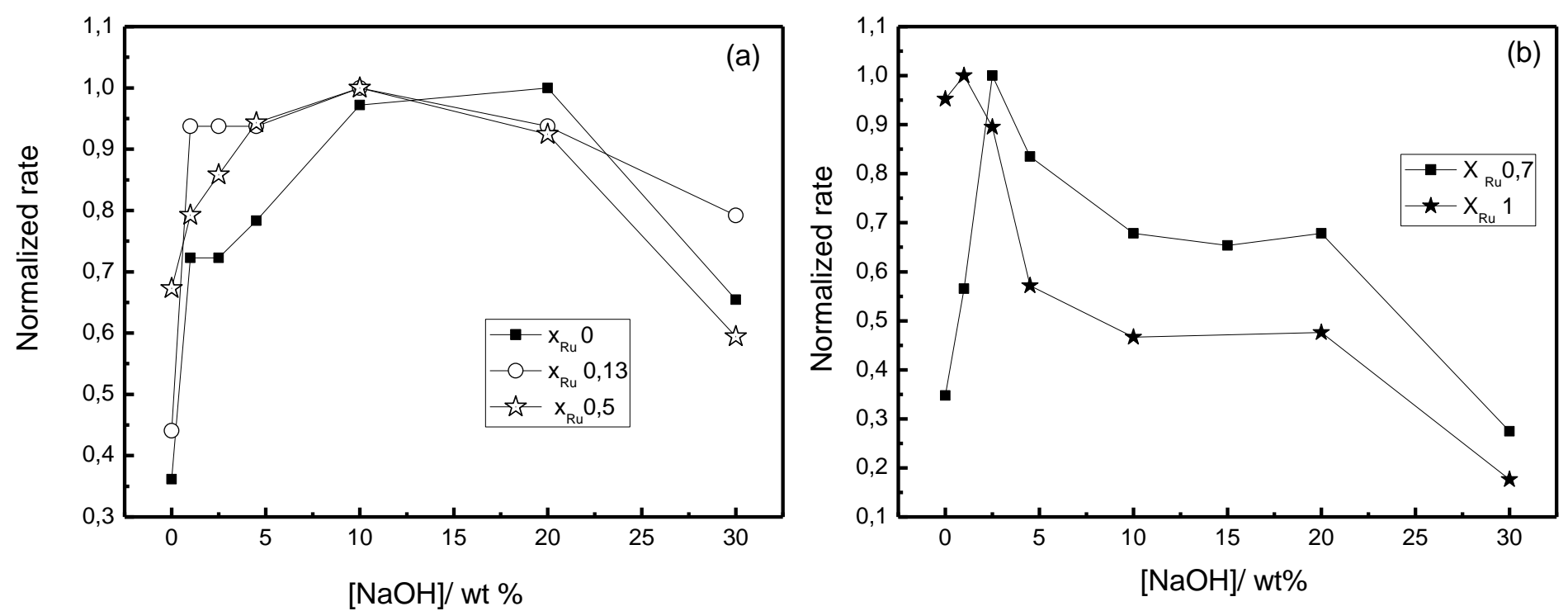


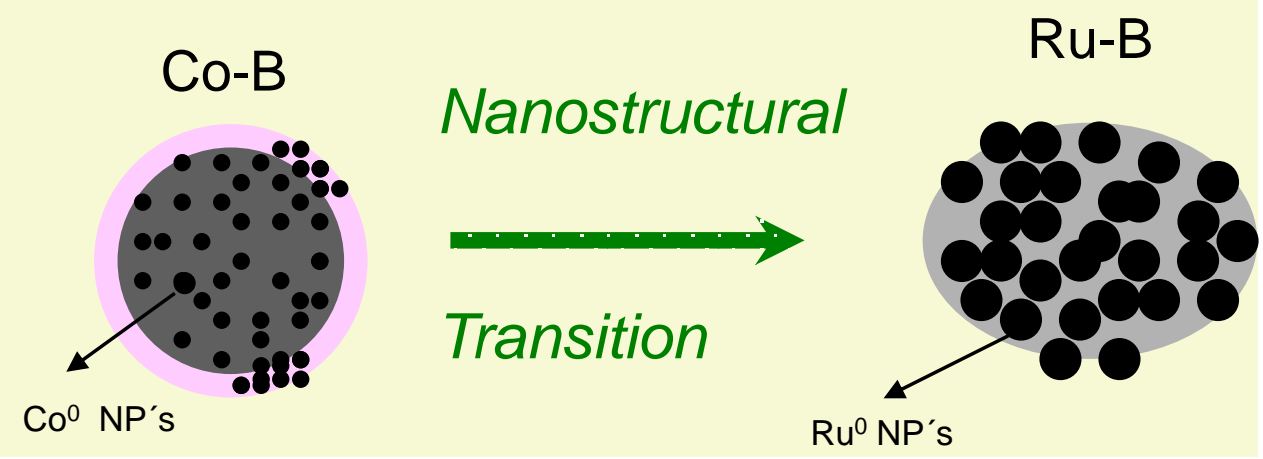




\section{Highlights}

Activity for hydrogen generation of Co-B catalysts is enhanced by small amounts of Ru Nanostructure of Co-Ru-B catalysts is related to boron-metal chemistry

Co-Ru-B catatalysts isostructural to Co-B. Nanostructural transition occurs for Ru-B

Cobalt segregation and $\mathrm{Ru}$ dispersion explain the synergistic effect

The effect is not universal but $\left[\mathrm{OH}^{-}\right]$dependant 
Supplementary Material
Click here to download Supplementary Material: SUPPORTING INFORMATION.doc

Supplementary Material
Click here to download Supplementary Material: SUPPORTING INFORMATION.doc

作

(1)

(1)

(1)

(1)

(1)

(1) . . . . . . . . . . . .

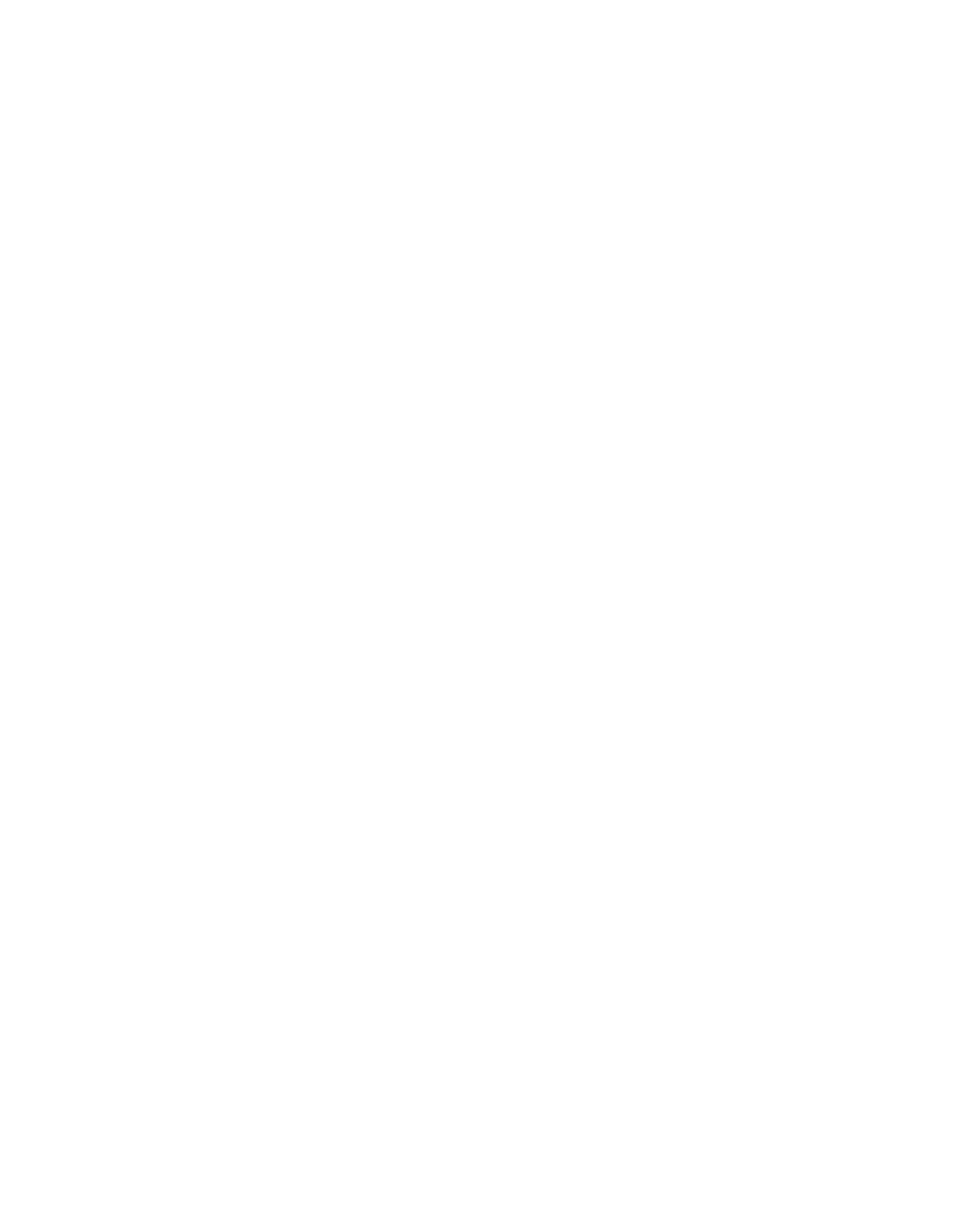

